\title{
Interdependence and Cooperation in Daily Life
}

Simon Columbus ${ }^{1 \dagger}$, Catherine Molho ${ }^{1,2,3 \dagger^{*}}$, Francesca Righetti ${ }^{1}$, Daniel Balliet ${ }^{1}$

${ }^{1}$ VU Amsterdam

${ }^{2}$ Institute for Advanced Study in Toulouse

${ }^{3}$ University of Toulouse Capitole

$\dagger$ These authors contributed equally to this work.

This paper has been accepted for publication at the Journal of Personality and Social Psychology (April 13, 2020). This version has not been copy-edited.

Please cite this version as:

Columbus, S., Molho, C., Righetti, F., \& Balliet, D. (in press). Interdependence and cooperation in daily life. Journal of Personality and Social Psychology. doi: $10.1037 /$ pspi0000253

* Corresponding author: Catherine Molho, Université Toulouse 1 Capitole, 1, Esplanade de l'Université, 31080 Toulouse, France. Email: catherine.molho@iast.fr

(C) 2020, American Psychological Association. This paper is not the copy of record and may not exactly replicate the final, authoritative version of the article. The final article will be available, upon publication, via its DOI: $10.1037 /$ pspi0000253 
Authors' Note: The authors would like to thank Robert Böhm, Reinout de Vries, Wilhelm Hoffmann, Jeff Joireman, Hannes Rusch, Josh Tybur, Paul van Lange, Mariko Visserman, Junhui $\mathrm{Wu}$, participants at workshops and conferences in Leiden, Lille, and Sedona, and three anonymous reviewers for discussion and helpful comments. Data for the Interdependence in Daily Life study were collected with help from Mina Ahrary, Tim Alkemade, Margriet Bentvelzen, Mike Bond, Terence Dores Cruz, Valeria Gawronski, Meriç Güzelant, Maaike Homan, Zeynep Konuksever, Nelli Kossenko, Antonis Koutsoumpis, Dyon Masrom, Sahar Mohmand, Bas Polder, Manouk Themmen, Esther Tieleman, S1la Ünal, Amber van Duijn, and Valentina Villa.

This research was supported by an ERC-Starting Grant (\#635356) awarded to Daniel Balliet. Catherine Molho acknowledges IAST funding from ANR under grant ANR-17EURE-0010 (Investissements d'Avenir program). 


\begin{abstract}
Philosophers and scientists have long debated the nature of human social interactions and the prevalence of mutual dependence, conflict of interests, and power asymmetry in social situations. Yet, there is surprisingly little empirical work documenting the patterns of interdependence that people experience in daily life. We use experience sampling to study how people think about three dimensions of interdependence in daily life and how these dimensions relate to cooperation. In Study 1, 139 romantic couples $(n=278)$ reported on situations experienced with their partner $(k=6,766)$; in Study 2, individuals $(n=284)$ reported on situations experienced with any other person $(k=7,248)$, over the course of one week. Across both samples, we found that most social interactions were perceived as containing moderate mutual dependence, equal power, and corresponding interests. When couples reported on the same situation (Study 1), they largely agreed on their experienced interdependence and cooperation, suggesting that their reports reflect an underlying shared reality. In daily interactions across both samples, higher mutual dependence and lower conflict of interests were associated with more cooperation, whereas relative power was not directly related to cooperation. These associations replicated in laboratory experiments (Study 2). In daily life, high mutual dependence and high relative power exacerbated the negative relation between conflict of interests and cooperation. Finally, prevalent patterns of interdependence and the experience of specific interdependent situations affected multiple relationship outcomes. Our findings stress the importance of studying a diverse array of interdependent situations - and especially situations with corresponding interests — to better understand cooperation in daily life.
\end{abstract}

Keywords: interdependence, cooperation, conflict, power, experience sampling 


\section{Interdependence and Cooperation in Daily Life}

Centuries of philosophical debate and scientific inquiry have attempted to understand the nature of human social interactions. Like Hobbes, one perspective pictures human life as a "war of all against all", marked by fleeting social interactions, conflicts of interests, and power asymmetries (Hardin, 1968; Hobbes, 1651/2013; Pinker, 2011). Another, competing perspective follows Rousseau in portraying human life as intensely social, filled with opportunities for mutual gain, and egalitarian (Boehm, 2009; Rousseau, 1754/2004; Skyrms, 2004; Tomasello, Melis, Tennie, Wyman, \& Herrmann, 2012). Thus, these two perspectives differ in their view of the recurring patterns of interdependent situations (i.e., situations in which people can influence each other's outcomes) that people encounter throughout their lives. For example, the Hobbesian perspective emphasizes the importance of studying situations involving conflicting interests (like the Prisoner's Dilemma; Axelrod, 1984; Rapoport \& Chammah, 1965), whereas the Rousseauian perspective emphasizes the need to study situations involving more corresponding interests (like the Stag Hunt; Skyrms, 2004; Thomas, DeScioli, Haque, \& Pinker, 2014).

Importantly, these two philosophical perspectives correspond to psychological theory on the structure of interdependence in social interactions. According to Interdependence Theory (Kelley et al., 2003), any social situation can be described along at least three dimensions: mutual dependence (i.e., degree to which each person's outcomes are determined by how the self and others behave), conflict of interests (i.e., degree to which the best outcome for one person results in the worst outcome for another person), and relative power (i.e., degree to which an individual can unilaterally determine his/her own and others' outcomes). Indeed, people have an ability to perceive differences between situations along these dimensions, and their perceptions of interdependence shape when and with whom they cooperate (i.e., when they behave in ways that benefit others; Columbus, Münich, \& Gerpott, 
2020; Gerpott, Balliet, Columbus, Molho, \& de Vries, 2018; Halevy, Chou, \& Murnighan, 2012; Halevy \& Phillips, 2015; Kelley \& Thibaut, 1978; Smith \& Hofmann, 2016).

Of course, throughout their daily lives, people can experience an enormous variety of interdependent situations with romantic partners, friends, colleagues, and strangers. Previous theory and empirical research have made specific assumptions about the prevalence and impact of different interdependent situations. As illustrated earlier, some philosophical perspectives have proposed that situations with mutual dependence, corresponding interests, and symmetric power may be more frequent; conversely, others have emphasized the prevalence of independence, conflicts of interests, and asymmetric power in human social interactions. Additionally, scholars have prioritized the study of certain situations, such as those involving high conflict of interests (like the Prisoner's Dilemma), based on the notion that they are highly diagnostic of others' traits, motives, and future behaviors and that they have important consequences for cooperation. Thus, an analysis of the interdependent situations people experience in daily life can inform debates about the prevalence of multiple interdependence dimensions and guide research towards the study of frequent and/or diagnostic situations. Importantly, a variety of interdependent situations can be diagnostic and have both immediate and long-term impact on relationship outcomes (e.g., trust and commitment, Simpson, 2007; Thielmann, Spadaro, \& Balliet, 2020; Wieselquist, Rusbult, Foster, \& Agnew, 1999).

To date, we know very little about how people experience different dimensions of interdependence in daily life situations, and how their perceptions of different interdependence dimensions uniquely relate to cooperation, as well as future interpersonal attitudes and behaviors. This is unfortunate because, as psychologists have long recognized, the subjective experience and construal of situations can exert a strong influence on behavior (Allport, 1937; Funder, 2016; Halevy \& Phillips, 2015; Murray, 1938; Rauthmann, Sherman, 
$\&$ Funder, 2015), and theory and research suggest that perceived interdependence may have an even stronger relation with how people behave than objective interdependence (Gerpott et al., 2018; Kelley \& Thibaut, 1978; Thompson \& Hastie, 1990). Understanding people’s everyday experiences of interdependence can guide researchers' choice of situations to scrutinize (e.g., situations with more versus less conflicting interests), and it can enrich our understanding of when and how people cooperate in close relationships, organizations, and interactions with strangers (de Dreu, 2010; Rusbult \& van Lange, 2003).

Here, we report two studies that use a multidimensional approach to document people's experiences of mutual dependence, conflict of interests, and relative power in daily life, as well as their implications for cooperation and relationship outcomes. This approach allows us to make four contributions. First, using experience sampling of situations in the daily lives of romantic partners and individuals we describe the pattern of interdependence they experience across situations. We then compare people's construal of interdependence in daily life situations to their perceptions of experimental games commonly used to study cooperation. Second, we study agreement and accuracy in people's perceptions of interdependence, by estimating the degree to which romantic partners have similar perceptions of interdependence within the same daily life situations, and by testing whether perceptions of interdependence track objective situational differences across experimental tasks. Third, we examine whether each dimension of interdependence is uniquely associated with cooperation, and whether interactions between multiple dimensions of interdependence explain additional variance in cooperation. We further attempt to replicate the relationships between interdependence and cooperation in laboratory experiments. Fourth, we use daily life data from romantic couples to examine the downstream consequences of interdependence for future interpersonal outcomes, including trust, commitment, and relationship satisfaction. 


\section{A Multidimensional Model of Situational Interdependence}

All social interactions are characterized by some form of interdependence, that is, a specific pattern of how individuals' own and other's actions affect each person's outcomes. Although each social interaction may be unique, there are nonetheless important dimensions that can be used to describe similarities and differences in interdependence across diverse social interactions (Kelley et al., 2003). These dimensions were described by Kelley and Thibaut (1978), who studied the most simplified expression of an interdependent situation, a $2 \times 2$ matrix, whereby each person has two behavioral options, and the outcome of the interaction is dependent on the actions taken by each person. For an example, consider a couple, Ahmad and Bouke, who each face a choice to clean, or not clean, their common home. In this case, each person's actions may affect both their own and the other's satisfaction with the state of affairs. Kelley and Thibaut (1978) decomposed the variance in each person's outcomes in interdependent interactions like this one by applying the logic of analysis of variance. This approach identified four dimensions that characterize interdependent situations: mutual dependence, conflict of interests, relative power, and coordination. $^{1}$

Mutual dependence. Situations vary in the degree to which people's outcomes are determined by how each person behaves. In some situations, people are mutually (and symmetrically) dependent on each other, such that each person's outcomes are determined by a combination of own and others' behavior. In other situations, people are fully independent - they completely control their own outcomes. In our example, if Ahmad is unaffected by whether Bouke helps with cleaning, and vice-versa, they are fully independent. Conversely, if they are affected by each other's actions - such that each of them is resentful when the other does not clean, or grateful when the other does clean - then Ahmad and Bouke are mutually dependent. Indeed, variability in the experience of mutual dependence 
has been recognized to occur across interactions in close relationships (Kelley et al., 2003; Rusbult \& van Lange, 2003), in organizational work tasks (Pearce \& Gregersen, 1991), and across interactions between members of a society (Yamagishi, Jin, \& Kiyonari, 1999).

Conflict of interests. Conflicting interests occur when one person's best outcome is another person's worst outcome. Conversely, in situations of corresponding interests, the same outcome can satisfy both persons. Situations can vary from completely corresponding to completely conflicting outcomes, and are most often marked by a mix of conflict and correspondence of outcomes. Returning to our example, Ahmad and Bouke may both enjoy cleaning together, in which case they have corresponding interests. What is good for Ahmad is also good for Bouke. However, in another case, Bouke prefers for Ahmad to do the cleaning while enjoying his time off, but Ahmad would like to rest while Bouke does the cleaning. In this case, there exists a conflict of interests: the preferred option for one partner is different from the preferred option for the other partner. Variation in conflict of interests is known to affect behaviors and outcomes in close relationships (Aktipis et al., 2018; Murray \& Holmes, 2009), within organizations and during work tasks (de Dreu \& Weingart, 2003; Janssen, van de Vliert, \& Veenstra, 1999), and generally among members of society, such as in the provision of public goods and resource conservation (Parks, Joireman, \& van Lange, 2013).

Relative power. Power differences occur when one person depends more on the actions of another than vice-versa. In other words, relative power equates to asymmetric dependence in a situation (Fiske, 2010; Galinsky, Rucker, \& Magee, 2015), and the actions of a person in high power, relative to their low power counterpart, can completely determine their own and the other's outcomes. Conversely, the outcomes of a person in low power are relatively more determined by the actions of the powerful than by their own actions. In our example, this may occur when Ahmad does not care whether Bouke helps with cleaning, but 
Bouke feels hurt when Ahmad does not do his part: In this case, Ahmad has greater control over Bouke's outcomes than vice-versa. People commonly experience situations with power differences within close relationships (Overall, Hammond, McNulty, \& Finkel, 2016; Righetti et al., 2015), organizations (Astley \& Sachdeva, 1984; Halevy, Chou, \& Galinsky, 2011) and society at large (Kraus \& Keltner, 2009; Smith \& Hofmann, 2016).

Coordination. Situations also vary in how much an actor's behavior can influence how their partner's behavior affects their own outcomes (i.e., the basis of interdependence; or social exchange; Kelley \& Thibaut, 1978). While variation along this dimension of interdependence might have implications for cooperation, previous work suggests that people are not able to represent and distinguish experimental and daily life situations as containing different degrees of coordination (see Gerpott et al., 2018). This might just mean that people have trouble consciously processing and/or verbally articulating differences based on coordination. Nevertheless, because our method here relies on measuring people's subjective construal of interdependence, we do not consider this dimension further.

\section{Interdependence in Daily Life}

Descriptive research on the patterns of situations people experience in daily life can guide researchers towards models and paradigms that can explain social behavior within its natural context. Descriptive research can (1) document facts that theory must explain (Asch, 1959), (2) stimulate theory development by providing insights about variation in behavior across natural settings, and (3) enable researchers to generate experimental designs that better model the ecology in which behavior is situated (see Rozin, 2001, 2006). For example, in the context of cooperation research, this means that understanding the frequency of conflict versus correspondence of interests can be key to identifying potentially simpler, easier solutions to promoting cooperation in daily life. 
To date, there is little empirical work describing the patterns of interdependence that are most common in daily life. Instead, research on interdependent situations has largely been driven by judgments of which situations are particularly impactful within interpersonal relationships (e.g., Kelley et al., 2003) or pose the greatest challenges to cooperation (Fehr \& Gächter, 2002; Rapoport \& Chammah, 1965; Thielmann et al., 2020). Indeed, experimental work has provided key insights into solutions to promote cooperation in such challenging circumstances, i.e., when individuals do not have high stakes in each other's well-being or when their interests conflict (as in Prisoner's Dilemmas; van Lange, Balliet, Parks, \& van Vugt, 2014). However, both impact and frequency can help us understand how cooperation is achieved and maintained in daily life. People do not always face situations that are unfavorable to cooperation, or pose the challenges mounted by the Prisoner's Dilemma (Cronk \& Leech, 2013; Skyrms, 2004; Tomasello et al., 2012). Thus, it is also important to identify simpler strategies to promote cooperation (e.g., ensuring common knowledge of intentions) in more mundane or benign situations, where individuals are mutually (and equally) dependent or have corresponding interests. In sum, studying how people experience mutual dependence, conflict of interests, and relative power provides a basis for understanding the structure of interdependence in daily life, and can identify strategies to promote cooperation in frequently experienced situations as well as in highly impactful, challenging situations.

\section{Agreement and Accuracy in Subjective Interdependence}

Interdependence Theory proposes that mutual dependence, conflict of interests, and relative power can be used to describe the objective properties of social situations (Kelley et al., 2003). However, in daily life people rarely possess knowledge of the objective interdependence underlying social interactions. Nonetheless, people may subjectively construe of the underlying interdependence in a situation, and these subjective perceptions of 
interdependence can themselves strongly determine how people behave (Columbus, Münich, \& Gerpott, 2020; Kelley \& Thibaut, 1978). This aligns with models of situation construal that suggest that the perception of situations is shaped by both objective properties of the situation and traits/states of the perceiver, and that the subjective perception of situations can have a unique effect on behavior, alongside the effects of the objective situation and the person (Funder, 2016; Rauthmann, Sherman, \& Funder, 2015).

Functional Interdependence Theory proposes that people have an ability to use verbal and nonverbal cues occurring in social interactions to make inferences about mutual dependence, conflict of interests, and relative power (Balliet, Tybur, \& van Lange, 2017). Recent work has found that people's perceptions of interdependence in social situations are organized along these three dimensions (Gerpott et al., 2018). Such evidence is further supported by research across the social sciences suggesting that people know when they depend on others (reflected in feelings of relationship closeness, Berscheid, Snyder, \& Omoto, 1989; and group entitativity, Gaertner \& Schopler, 1998), that people correctly evaluate situations as containing more or less conflict of interests (Halevy et al., 2012; Halevy \& Phillips, 2015; but see Thompson \& Hastie, 1990), and that people understand when they possess relatively high or low power in social interactions (Fiske, 2010; Galinsky et al., 2015; Molho, Balliet, \& Wu, 2019; Sivanathan, Pillutla, \& Murnighan, 2008). Thus, perceptions of interdependence can be meaningfully tied to the underlying, objective interdependence in social interactions, and so people should share similar inferences about the interdependence that characterizes a specific situation (Balliet et al., 2017). Here, we utilize a multidimensional measure of how people perceive their interdependence in a situation, in order to study whether romantic couples share similar perceptions of interdependence, and whether perceptions of interdependence track objective interdependence across controlled lab experiments. 


\section{Interdependence and Cooperation in Daily Life}

How people think about their mutual dependence, conflict of interests, and relative power in a situation can affect when they decide to cooperate. Mutual dependence may enable cooperation, especially when individuals have high stakes in the well-being of their interaction partner (Aktipis et al., 2018; Roberts, 2005). In romantic couples, dependence promotes commitment and pro-relationship behaviors (Rusbult \& van Lange, 2003). Similarly, co-workers engage in greater prosocial behaviors when they feel mutually dependent (Bachrach, Powell, Bendoly, \& Richey, 2006), and people behave more cooperatively even towards strangers when they perceive themselves as mutually dependent with them (Yamagishi et al., 1999).

In contrast, conflict of interests can make cooperation harder to achieve (de Dreu, 2010; Rapoport \& Chammah, 1965). Indeed, romantic partners are thought to sacrifice less for their partner in high conflict-of-interest situations (Righetti \& Impett, 2017), organizational teams experiencing high task conflict perform worse (de Dreu \& Weingart, 2003), and experimental research finds that strangers cooperate less in situations with higher conflict of interests (Rapoport \& Chammah, 1965). Thus, perceived conflict of interests is the root of manifest conflict, both between individuals and between groups (de Dreu, 2010; Halevy \& Phillips, 2015; Thompson \& Hastie, 1990).

Power differences in social interactions can carry substantial consequences for cognition, emotion, and behavior (Fiske, 2010; Galinsky et al., 2015). High power may enable individuals to coerce outcomes of their liking, while individuals holding less power may have to behave more cooperatively. Indeed, in romantic couples, powerholders behave less cooperatively (Righetti et al., 2015). In experimental situations that simulate leaderfollower relationships, those who possess power make more selfish decisions (Bendahan, Zehnder, Pralong, \& Antonakis, 2015), and in negotiations and social dilemma situations 
with strangers, individuals holding power, or merely perceiving themselves as holding more power, make smaller concessions than their low-power counterparts (e.g., de Cremer \& van Dijk, 2005; for a meta-analysis, see Nieper, Balliet, Molho, \& van Kleef, 2019).

In summary, based on past theory and research it can be expected that people will behave more cooperatively in situations that contain higher mutual dependence and lower conflict of interests, and in which they possess lower relative power. Thus far, research testing how variation along these dimensions of interdependence relates to cooperation has considered only single interdependence dimensions in isolation. For example, theory and research on power is largely independent from existing work on mutual dependence and conflict of interests (for exceptions see, Greer, van Bunderen, \& Yu, 2017; van Kleef, de Dreu, \& Manstead, 2010). ${ }^{2}$ This is unfortunate, because the three dimensions of interdependence can be confounded, for example, such that individuals who experience low power in a situation also experience higher amounts of conflict of interests and less mutual dependence (Gerpott et al., 2018). Further, specific multidimensional patterns of interdependence may promote or undermine cooperation. For example, relative power may be negatively associated with cooperation when conflict of interest is high (Greer et al., 2017; Ronay, Greenaway, Anicich, \& Galinsky, 2012) but have no-or even a positive-effect when interests are corresponding. Here, we study how each of three fundamental interdependence dimensions uniquely relates to cooperation within ecologically valid, daily life situations. Our multidimensional approach to the study of interdependence in daily life allows us to further study whether these dimensions interact in ways that can explain additional variance in cooperation.

\section{Interdependence and Relationship Outcomes}

Patterns of interdependence may affect behavior within the given situation, but they may also influence how people perceive and act towards others in future situations. Indeed, 
research in the tradition of Interdependence Theory has focused on 'diagnostic situations', in which others' behavior reveals something about their personality or attitude towards their interaction partner (Holmes, 2002; Reis, 2008). For example, how one partner behaves in a conflict-of-interests situation can be diagnostic of that partner's concern for your welfare (van Lange, Rusbult, Drigotas, Arriaga, Witcher, \& Cox, 1997), and so a partner's cooperative behavior in a conflict-of-interests situation can promote future trust (Balliet \& van Lange, 2013; Wieselquist et al., 1999). In a similar vein, situations involving corresponding interests may afford the expression of exploitative traits (e.g., Machiavellianism, Competitiveness; Thielmann et al., 2020), and a partner's non-cooperative behavior in such benign situations may have adverse effects on relationship outcomes over time.

Importantly, while diagnostic situations have been assumed to be rare, yet highly impactful on relationship dynamics and outcomes, everyday experiences of mutual dependence, conflict of interests, and relative power may have accumulative effects over time. In close relationships, the experience of dependence is linked to relationship satisfaction and relationship persistence (Le \& Agnew, 2003; Le, Dove, Agnew, Korn, \& Mutso, 2010). Conflicts of interests are associated with a wide variety of negative emotions, attitudes, and behaviors (Durante, Eastwick, Finkel, Gangestad, \& Simpson, 2016; Righetti, Gere, Hofmann, Visserman, \& van Lange, 2016; Simpson, Rholes, \& Phillips, 1996), and asymmetry in power has been linked to reduced investments, commitment, and relationship satisfaction (Lennon, Stewart, \& Ledermann, 2013; Murray, Holmes, \& Pinkus, 2010; Righetti et al., 2015; Simpson, Farrell, Oriña, \& Rothman, 2015). Here, we sample situations experienced by romantic couples in daily life, which allows us to study both the prevalent patterns of interdependence and the impact of different interdependent situations on multiple outcomes, including trust, relationship satisfaction and commitment. 


\section{Overview of Studies}

Across two community samples, we applied experience sampling techniques to randomly sample social situations people experience in their daily lives (seven times a day, for seven consecutive days). In Study 1, we had romantic couples report on the most recent situations they experienced with their romantic partner, and in Study 2 participants reported the most recent situations they experienced with any other person, such as close others, colleagues at work, and strangers. Participants reported their perceptions of interdependence and cooperative behavior in those daily life situations. We used a multidimensional instrument (Situational Interdependence Scale; Gerpott et al., 2018) to measure perceptions of interdependence along the dimensions of mutual dependence, conflict of interests, and relative power. In Study 2, we also measured how people thought about their interdependence with others in prototypical economic exchange tasks used to study cooperation in the laboratory, such as the Prisoner's Dilemma and the Stag Hunt. This allowed us to (1) compare how people think about these experimental situations with their perceptions of situations they experience in daily life, and (2) replicate the associations between perceived interdependence and cooperation in a controlled experimental setting.

Overall, these methods enable us to achieve several goals. First, we can document and describe the patterns of interdependence that people experience in daily life along the dimensions of mutual dependence, conflict of interests and relative power. Second, we can test the idea that perceptions of interdependence are interpersonally shared, and so may track objective features of reality. In this regard, we study the overlap in how romantic partners perceive their interdependence and cooperation in the same daily life situations. Third, we can use longitudinal, daily life data to test how multiple interdependence dimensions relate to changes in trust, commitment, and relationship satisfaction over time within a relationship. Finally, across both our studies, we can test predictions that situations with higher mutual 
dependence, lower conflict of interests, and lower relative power, will be associated with higher rates of cooperation. In so doing, we can examine whether each interdependence dimension has a unique association with cooperation and whether different dimensions interact to predict cooperation. We test the associations between interdependence dimensions and cooperation using both experience sampling data (Study 1 and 2) and experimental tasks (Study 2). Using these methods, we can additionally compare how people think about commonly used experimental games to study cooperation (i.e., the Prisoner's Dilemma and Stag Hunt) to how people think about the interdependent situations they experience in daily life.

\section{Study 1: Interdependence in Daily Life-Romantic Couples}

In Study 1, we focus on the interdependent situations people experience with their romantic partner — arguably the most important and most deeply interdependent relationship in people's lives. We recruited a sample of romantic couples and had them report on the most recent situations they experienced with their partner. A focus on romantic couples allowed us to obtain data from two individuals reporting on the same situation, and these data can be used to assess the degree of convergence in how partners perceive their interdependence and cooperation in the same situation. We can use reports on the same situation to assess how an actor's perceived mutual dependence, conflict of interests, and relative power in a situation can predict their partner's report of the actor's cooperative behavior in that situation. In this way, we do not rely on self-reports of perceived interdependence and cooperative behavior from the same person. Further, the study of romantic couples allows us to examine how the experience of different interdependent situations affects changes in attitudes towards one's partner and one's relationship over time. 


\section{Sample and Data Collection}

We collected data from a Dutch community sample of romantic couples ( $n=278$; $50.7 \%$ male; $M_{\text {age }}=32.04$ years, $S D=13.56$, range $\left.18-79\right)$. We originally sought to recruit 150 couples, based on standards in the existing literature (e.g., Righetti et al., 2016; Smith \& Hofmann, 2016; see Conner \& Mehl, 2011) and financial and practical constraints. The final sample size deviates from this target due to no-shows of recruited participants. We did not conduct a formal power analysis. Power analyses for linear mixed models are based on simulation and require setting a number of parameters that quickly increases with model complexity (Green \& MacLeod, 2016). In the absence of reliable information on these parameters, we decided against a formal power analysis. For further details on our rationale, see the SI. No analyses were conducted before data collection was completed. All materials, data, and analysis syntax for the study can be found on the Open Science Framework (OSF; https://osf.io/dwbz3/; for further details, see also Columbus, Molho, Righetti, and Balliet, in prep.).

Among participants, $29.5 \%$ had a university education, $32.7 \%$ had completed vocational training, and $35.6 \%$ had completed secondary education. Further, $89.2 \%$ reported being born in the Netherlands. The reported median monthly net income was $€ 1,200-1,399$, and a significant proportion reported monthly net incomes above 2,500€ (14.0\%). Overall, although the sample was skewed towards younger ages, it was heterogeneous in terms of age, education, and income.

\section{Procedure}

Participants were recruited via online panels. During an intake session, they completed personality and attitude surveys and were instructed for the experience sampling phase. Then, participants completed a one-week experience sampling phase in which we collected 
descriptions of daily life situations. Finally, participants completed a follow-up survey one week after the experience sampling phase.

Intake session. In the laboratory, participants first completed individual difference questionnaires, demographic questions, and relationship-specific measures. Within each of these three sets of questionnaires, the order of measures was randomized; item order was randomized within each questionnaire. This first part lasted for approximately 45 minutes. After a break, participants received detailed instructions for a series of incentivized economic games with their partner (not analyzed here); this part took approximately 30 minutes to complete. Finally, participants received detailed instructions about the experience sampling phase. Research assistants read a script and used slides to present and explain all questionnaires included in the experience sampling surveys.

Participants were given a detailed description of the kinds of situations to report. Specifically, we asked participants to report a situation they had "experienced with their partner". We defined this as either a situation in which they had directly interacted with their partner, including instances where the partner was not physically present, or a situation in which their partner was physically present, even if they did not interact. We also stressed that participants were to report situations independent of their importance or their interdependence with their partner in the situation. The exact text of the instructions can be found in the Procedures document on the OSF.

Experience sampling phase. For seven consecutive days, participants received seven messages a day between 08:00 and 22:00. This window was divided into seven blocks of two hours, and participants received a message at a random time within each block (with a minimum of 45 minutes between messages). Partners were always contacted simultaneously, but were instructed not to communicate about their responses. If participants did not open the link in the message, a reminder was sent after 15 minutes. Survey links remained open for 45 
minutes. The median time until opening the link was 3 minutes in both samples. Each link directed participants to a short survey (median time to completion was 2:36 minutes).

Participants were first asked whether they had experienced a situation with their partner since responding to the last questionnaire. If so, they were asked to report on the last situation they had experienced with their partner ("Partner" stream). If not, participants were asked whether they had experienced a situation with another person in this period. If so, they were asked to report on the last situation they had experienced with another person ("Social" stream). If they had not experienced a situation with another person, participants were asked to report on the last situation they experienced before they began filling in the questionnaire (“Nonsocial" stream).

The overall response rates were $81.6 \%$, and median per-subject response rates were even higher (89.8\%). Overall, we obtained 11,100 unique responses. There were 6,766 responses in the "Partner" stream ("Social" = 2,216; "Nonsocial" = 2,119).

Matching of situations. All responses to the same signal $(k=5,148$ reports in 2,574 instances) were coded to determine whether partners had reported on the same situation. A Dutch native speaker was trained to code each pair of reports as referring to the same situation or not, based on the written situation descriptions. 100 situations were sampled and classified by a second trained coder to test for interrater reliability (Cohen's $\kappa=.92)$. This resulted in 3,562 matched reports referring to 1,781 situations reported by 131 couples.

Partners agreed in most situations that they were both present (84.4\%) and rarely both indicated that the other was not present (1.6\%). When they disagreed on each other's presence, partners reported greater conflict of interests relative to situations in which both were present, though there were no differences in mutual dependence and relative power. Importantly, patterns of associations between reported interdependence and cooperative behavior were similar when partners agreed or disagreed on each other's presence (see SI). 
Follow-up survey. Seven days after the end of their experience sampling phase, participants were sent a follow-up survey by email. If participants had not completed the survey, they received a reminder three days after the first message. The overall response rate was $75.18 \%$ (203 complete responses, 6 partial; average time to completion 10 days after the experience sampling phase). The follow-up survey contained a number of relationshipspecific questionnaires.

Participant earnings. Participants were paid 20 euros for participating in the intake session, up to 10 euros based on their own and others' decisions in economic games, 0.50 euros per completed experience sampling survey, and a bonus of 20 euros for responding to at least $75 \%$ of the experience sampling surveys. Participants earned an average of 63.65 euros $(S D=12.27)$.

\section{Measures}

Intake and follow-up. We measured commitment and relationship satisfaction using the Investment Model Scale (Rusbult, Martz, \& Agnew, 1998). We used four global items to measure commitment (e.g., "I want our relationship to last forever") and three to measure relationship satisfaction (e.g., "I feel satisfied with our relationship.”), which were answered on a seven-point Likert-type scale $(1=$ completely disagree, $7=$ completely agree $)$. The subscales were highly reliable (commitment: $\Omega_{t \text {.intake }}=.86, \Omega_{t . f o l l o w-u p}=.92$; relationship satisfaction: $\Omega_{\text {t.intake }}=.87, \Omega_{\text {t.follow-up }}=.84$ ).

Experience sampling phase. After participants had selected a situation, we asked them to report situation cues including the time and place of the situation (e.g., "at home", "at work", etc.). We further asked participants to describe the situation in one to three sentences, focusing on what they did and what their partner did (examples of reported situations are available in Table S12 and on the OSF). Then, participants completed the 10-item Situational Interdependence Scale (SIS) with reference to their partner in the situation they described. 
Table 1. Items used to measure three interdependence dimensions in the short SIS scale (Study 1 and 2). All items were answered on a 5-point Likert scale (Mutual dependence and conflict of interests: $1=$ completely agree, $5=$ completely disagree; relative power: $1=$ completely the other, $3=$ neither one nor the other, $5=$ completely myself).

\begin{tabular}{|c|c|c|}
\hline Dimensions & Definitions & Items \\
\hline $\begin{array}{l}\text { Mutual } \\
\text { Dependence }\end{array}$ & $\begin{array}{l}\text { The degree to which both } \\
\text { individuals mutually } \\
\text { control each other's } \\
\text { outcomes. }\end{array}$ & $\begin{array}{l}\text { 1. What each of us does in this situation } \\
\text { affects the other. } \\
2 . \text { Whatever each of us does in this } \\
\text { situation, our actions will not affect the } \\
\text { other's outcomes. (R) }\end{array}$ \\
\hline $\begin{array}{l}\text { Conflict of } \\
\text { Interests }\end{array}$ & $\begin{array}{l}\text { The degree to which one } \\
\text { individual's gain is another } \\
\text { individual's loss (vs. } \\
\text { corresponding interests). }\end{array}$ & $\begin{array}{l}\text { 3. Our preferred outcomes in this situation } \\
\text { are conflicting. } \\
4 \text {. We can both obtain our preferred } \\
\text { outcomes. (R) }\end{array}$ \\
\hline Relative Power & $\begin{array}{l}\text { The degree to which one } \\
\text { individual has greater } \\
\text { control over their own and } \\
\text { the other's outcomes than } \\
\text { vice-versa. }\end{array}$ & $\begin{array}{l}\text { 5. Who do you feel has more power to } \\
\text { determine their own outcome in this } \\
\text { situation? } \\
\text { 6. Who has the least amount of influence } \\
\text { on the outcomes of this situation? (R) }\end{array}$ \\
\hline
\end{tabular}

Note: (R) indicates reverse-scored items.

The 10-item version of the SIS (Gerpott et al., 2018) has been designed to measure situation-specific perceptions of five interdependence dimensions. Here, we focus on the three dimensions of mutual dependence, conflict of interests, and relative power that represent quantifiable features of two-person, two-choice matrices (while the other two dimensions do not; Kelley et al., 2003). The short (10-item) version of the SIS measures each of these dimensions with two items, scored on 5-point Likert scales (see Table 1). These subscales have been found to be reliable and valid, with previous research establishing their construct, divergent, convergent, and criterion validity (Gerpott et al., 2018). We computed multilevel item correlations for each subscale accounting for dependence within couples and within individuals $(n=272, k=6,717)$. Item correlations were medium to large $(95 \%$ confidence intervals for multilevel correlations; mutual dependence: $r=[.32, .36]$, conflict of interests: $r=[.42, .46]$, relative power: $r=[.71, .73])$. We also assessed how reliably these measures assessed within-person change over time by computing $R_{C}$ (Bolger \& Laurenceau, 
2013; Cranford, Shrout, Iida, Rafaeli, Yip, \& Bolger, 2006). The reliability of change was acceptable to good (mutual dependence: .51; conflict of interests: .63; relative power: .84). For details, see SI.

Moreover, participants responded to two questions about their own and their partner's cooperation (i.e., to what extent their behavior benefited the other). Participant's used a 5point Likert scale, to indicate how costly versus beneficial (a) their own behavior was for their partner (i.e., own cooperation; ranging from $-2=$ costly to my partner to $2=$ beneficial to my partner, with a mid-point of $0=$ neutral) and (b) their partner's behavior was for themselves (i.e., other's cooperation; ranging from $-2=$ costly to myself to $2=$ beneficial to myself, with a mid-point of $0=n e u t r a l)$. Participants also responded to two items indicating their trust in their partner ("I trust my partner.") and their relationship satisfaction ("I am satisfied with my relationship.”). Both items were answered on five-point Likert-type scales $(1=$ completely disagree, $5=$ completely agree $)$. Finally, participants also responded to some questions not relevant to this research.

Data exclusion procedures. Across both studies, we did not remove any participants from analyses. $N$ s vary between analyses because some participants only completed part of the procedure (e.g., did not complete parts of the intake surveys or dropped out of the experience sampling phase without providing any responses). For the experience sampling data, for technical reasons participants could respond twice to the same survey. When they did so, we retained the first response (which should be unaffected by repeated responding). This was also the most complete response for all cases.

\section{Results}

Interdependence in the daily life of romantic couples. The experience sampling method enables us to document how randomly selected social situations in the daily lives of romantic couples vary along the dimensions of mutual dependence, conflict of interests, and 
relative power, and so describe the variety of interdependent situations people experience with their partner in daily life. First, we explored the distributions of participants' perceptions of interdependence along three dimensions through linear mixed models with random intercepts for subjects and couples. People's experiences varied from situation to situation on the dimensions of mutual dependence, conflict of interests, and relative power. Table 2 displays the variance components for each dimension of interdependence and shows that much more of this variance occurs between situations than between persons or between couples. More specifically, note that the within-person variance $\sigma^{2}$ is larger than the sum of between-subject variance and between-couple variance, indicating that perceptions of interdependence vary more between situations than between persons or couples. Importantly, within-person variance reflects both true variation between situations and measurement error.

Most situations experienced by romantic couples contained moderate mutual dependence $(\mathrm{Mdn}=3)$ and corresponding interests (Mdn =2; Fig. 1). People rarely reported situations with conflicting interests; out of all situations, only $7.25 \%$ were rated above the scale midpoint. Further, people mostly reported situations involving equal power $(\mathrm{Mdn}=3)$; $78.25 \%$ were rated at the scale midpoint, indicating that neither partner held more power than the other.

Table 2. Variance components of (standardized) mutual dependence, conflict of interests, and relative power at the level of situation, persons, and couples (Study 1).

\begin{tabular}{lrrr}
\hline \multicolumn{1}{c}{ Variance } & $\begin{array}{c}\text { Mutual } \\
\text { Dependence }\end{array}$ & $\begin{array}{c}\text { Conflict } \\
\text { of Interests }\end{array}$ & $\begin{array}{c}\text { Relative } \\
\text { Power }\end{array}$ \\
\hline Within-person $\sigma^{2}$ & .64 & .69 & .97 \\
Between-person $\tau_{00}^{2}$ & .07 & .14 & .25 \\
Between-couple $\varphi_{00}^{2}$ & .26 & .18 & .03
\end{tabular}

Note: Within-person variance reflects both true variation between situations and measurement error. $N=262, k=3,562$. 
Figure 1. The distribution of situations experienced in the daily life of romantic couple along mutual dependence, conflict of interests, and relative power (Study 1).

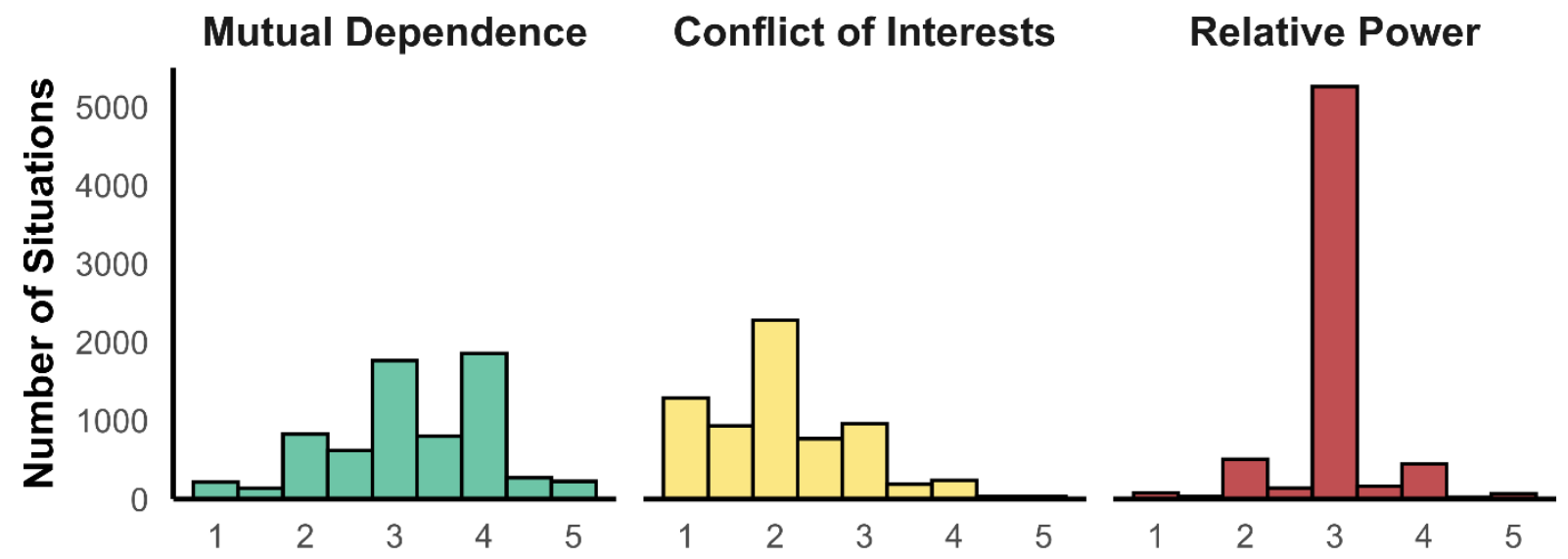

Note: The y-axis shows the total number of situations experienced by romantic couples. The $\mathrm{x}$-axis displays the value on reported mutual dependence $(1=$ independence, $5=$ mutual dependence), conflict of interests $(1=$ corresponding interests, $5=$ conflicting interests $)$ and relative power $(1=$ low, $3=$ equal, $5=$ high). $N=272, k=6,717$.

We calculated multilevel correlations between dimensions, accounting for dependence within couples and within individuals $(n=272, k=6,717)$. These revealed that mutual dependence had a small positive relation with conflict of interests, $r=.08, t(6715)=6.94, p<$ .001 , and no relation with relative power, $r-.02, t(6715)=-1.38, p=.167$. Conflict of interests had a small negative relation with relative power, $r=-.05, t(13620)=-4.51, p<$ .001 , indicating that perceptions of higher relative power in a situation are associated with experiencing less conflict of interests.

Overall, we found that people have richly varied experiences of interdependence in daily life with their romantic partner and that the bulk of this variation occurs across situations rather than between people and couples. However, there is also a clear central tendency for each dimension of interdependence, as the situations which couples experienced in their daily lives most frequently involved moderate mutual dependence, largely corresponding interests, and symmetric power. 
Interdependence as a shared reality in social interactions. If perceptions of interdependence reflect underlying properties of the world, we should expect partners to align in their construal of shared situations. We coded when romantic partners reported on their interdependence in the same situation. This data can be used to test the degree of agreement between partners' perceptions of interdependence across all three dimensions (Furr, 2008). We computed two indices of profile agreement for couples' responses (3,562 matched reports on 1,781 situations) on the six items measuring mutual dependence, conflict of interests, and relative power. Because the overall index is inflated by the normativeness of responses (e.g., because certain situations are particularly common), we also computed an index of distinctive profile agreement (Furr, 2008; see SI for details).

When romantic couples reported on the same situation, they strongly agreed in their perceptions of interdependence (overall profile agreement $q=.81, t(1,646)=6.02, p<.001$; distinctive profile agreement, $q=.33, t(1,646)=9.71, p<.001)$. This is comparable to selfother agreement on personality traits among friends (and only somewhat lower than among romantic partners) and exceeds the agreement between in situ and ex situ ratings based on written descriptions of situations (Allik, de Vries, \& Realo, 2016; Decuyper, De Bolle, \& De Fruyt, 2012; Decuyper, Gistelinck, Vergauwe, Pancorbo, \& De Fruyt, 2018; Gerpott et al., 2018; Lee \& Ashton, 2017; Sherman, Nave, \& Funder, 2010). The index of profile agreement considers how well partners align across all dimensions of interdependence within an average situation. To test how well couples agreed on each dimension in isolation, we correlated partners' perceptions on each individual dimension while including couples as a random factor. This yields correlations between partners' perceptions of interdependence across all situations they experienced together. This revealed similar associations for mutual dependence, $r=.15, t(1770)=6.25, p<.001$, conflict of interests, $r=.30, t(1770)=13.28, p$ $<.001$, and relative power, $r=.27, t(1770)=11.68, p<.001$. Except for mutual dependence, 
these correlations are only slightly lower than typical correlations between partners' overall perceptions of their relationship (Brackett, Warner, \& Bosco, 2005; Pierce, Sarason, Sarason, Solky-Butzel, \& Nagle, 1997; Saffrey, Bartholomew, Scharfe, Henderson, \& Koopman, 2003). In sum, the consensus between romantic partners' perceptions of interdependence in the same situation suggests that interdependence perceptions track a shared underlying reality.

Cooperation in the daily life of romantic couples. Our experience sampling method allowed us to collect reports of own and others' cooperation in social situations in the daily lives of romantic couples. First, we examined the distributions of individuals' reports of their own and their romantic partner's cooperation. Higher scores on the measure of own cooperation meant that participants reported their behavior being more beneficial (rather than costly) to their partner. Higher scores on the measure of partner's cooperation similarly meant that participants reported their partner's behavior being more beneficial (rather than costly) to themselves. Participants rarely reported behaving in a non-cooperative manner $(5.05 \%$ of all situations rated below the scale midpoint), nor did they report their partner frequently being non-cooperative $(5.07 \%$ of all situations).

We also assessed the degree to which partners agreed in their perception of each other's cooperation (3,562 matched reports on 1,781 situations). Following Kenny, Kashy, and Cook (2006), we used SPSS (IBM Corp., 2017) to fit a linear mixed model with participants' reports of their partner's cooperation as a predictor of the partner's self-reported cooperation. We used a dual intercept model to estimate random intercepts separately for each dyad member and allow them to covary (see SI for details). These analyses reveal considerable self-other agreement on reported cooperation, $\beta=.36, S E=.02, t(2718.45)=22.48, p<.001$. This estimate is only slightly lower than a meta-analytic estimate of self-other agreement on prosocial behavior in a relationship as a whole $(r=.40$; Fletcher $\&$ Kerr, 2010). This 
indicates that self-reported own cooperation is often perceived as such by one's romantic partner, supporting the validity of the self-report measure as reflecting actual cooperative behaviors that are noticeable by others.

Perceptions of interdependence are associated with cooperation. Based on prior theory, we predicted that higher mutual dependence, lower conflict of interests, and lower relative power would be associated with more cooperative behavior in interactions between romantic partners. We used a dyadic model to test whether one partner's (the 'actor') perceptions of interdependence predicted their partner's report of the actor's cooperation (3,544 matched reports on 1,772 situations). This allows us to use distinct sources of measurement for the perception of the situation (through the actor) and the actor's behavior in the situation (through the partner). We fitted a standard model for dyadic longitudinal data analysis using SPSS to predict partners' perceptions of actors' cooperation. We entered actors' perceived mutual dependence, conflict of interests, and relative power as predictors in the fixed part of the model. In this and all following analyses, predictors were grand meancentered; analyses using person mean-centering yield comparable results (see SI). We used a dual intercept model to estimate random effects separately for each dyad member and allow them to covary. To ascertain that dyads were not distinguishable, we tested for sex effects by including the main effect and interaction with the three SIS variables, but no effects were significant (all $p>.05)$; therefore, we retained the indistinguishable dyad model.

The pattern of actors' perceptions of interdependence predicted their partners' perceptions of the actors' cooperative behavior. Specifically, conflict of interests was significantly and negatively associated with cooperative behavior, $\beta=-.13, S E=.02, t(3351)$ $=-8.06, p<.001$. In contrast, mutual dependence showed no significant association with cooperation, $\beta=.03, S E=.02, t(3501)=1.70, p=.088$, nor did relative power, $\beta=-.01, S E=$ $.01, t(2963)=-.51, p=.611$, Table 3 . In other words, a person's perceptions of conflict of 
interests predicted their cooperative behavior, as seen through the eyes of their partner. We replicated this pattern when examining how actors' perceptions of interdependence relate to actors' reports of (a) their own cooperation and (b) partners' cooperation, as well as (c) partners' perceptions of partners' own cooperation (see SI; Table S5). Across these three additional models, mutual dependence was significantly positively associated with cooperation, whereas conflict of interests was strongly negatively associated with cooperation. These findings are consistent with theoretical accounts of how variation in interdependence gives rise to differences in cooperation. In contrast to our expectations, perceived relative power did not relate to cooperation across all analyses.

Measuring multiple dimensions of interdependence also allowed us to explore interactions between mutual dependence, conflict of interests, and relative power predicting cooperation. To assess whether interactions between dimensions of interdependence explained further variance in cooperation, we fitted an additional model that included all interaction terms as fixed effects. We compared this against the main effects-only models using a log likelihood ratio test. The interaction terms explained about $0.4 \%$ of additional variance in partners' reports of actors' cooperative behavior, $X^{2}(4)=6.07, p=.073, \Delta R^{2}=$ .004 .

Table 3. Actors' reported mutual dependence, conflict of interests, and relative power predict partners' report of actors' cooperation (Study 1).

\begin{tabular}{lccccc}
\hline & $\boldsymbol{\beta}$ & $\boldsymbol{S E}$ & $\boldsymbol{d} \boldsymbol{f}$ & $\boldsymbol{t}$ & $\boldsymbol{p}$ \\
\hline Intercept & .01 & .04 & & & \\
$\begin{array}{l}\text { Mutual } \\
\text { Dependence }\end{array}$ & .03 & .02 & 3501 & 1.70 & .088 \\
$\begin{array}{l}\text { Conflict of } \\
\text { Interests }\end{array}$ & -.13 & .02 & 3351 & -8.06 & $<.001$ \\
Relative Power & -.01 & .01 & 2963 & -.51 & .611 \\
\hline
\end{tabular}


As in the models presented earlier, conflict of interests was negatively associated with partner's reports of actors' cooperation (Table S6). When including interactions in our model, we also find a significant, negative main effect of actors' relative power on partners' perceptions of actors' cooperation. Additionally, the effect of conflict of interests was moderated by mutual dependence and by the interaction of mutual dependence and relative power (i.e., a three-way interaction). Simple slopes for mutual dependence fixed to $\pm 1 S D$ show that the effect of conflict of interests was stronger when mutual dependence was high, $\beta$ $=-.17, S E=.02, t(3310.24)=-8.48, p<.001$, than when mutual dependence was low, $\beta=-$ $.09, S E=.02, t(3497.72)=-3.52, p<.001$. Moreover, there was an interaction between conflict of interests and relative power when people experienced high mutual dependence, $\beta$ $=-.04, S E=.01, t(3262.66)=-3.30, p=.001$, rather than low mutual dependence, $\beta=.02, S E$ $=.02, t(3326.16)=1.30, p=.195$. Further simple slopes analyses show that at high levels of mutual dependence, conflict of interests was more strongly negatively associated with actors' cooperation when the actor held high relative power, $\beta=-.21, S E=.03, t(3447.51)=-8.35, p$ $<.001$, rather than low relative power, $\beta=-.12, S E=.02, t(3406.50)=-5.63, p<.001$. In sum, conflict of interests was consistently associated with less cooperative behavior. This relationship was more pronounced the higher the mutual dependence in the situation. Finally, conflicts of interests were more negatively associated with cooperative behavior of individuals holding more relative power, though only in highly mutually dependent situation. This pattern largely replicated when we considered partners' reports of their own behavior and actors' reports of their own and their partners' behavior, though the effects of mutual dependence and relative power differed between models (see SI; Table S6).

Interdependence shapes relationship outcomes. Assessing perceptions of interdependence over an extended timespan also enabled us to explore how everyday situations influence relationship attitudes in the following situation and in the long term. 
Specifically, we first tested how partners' behavior in situations varying along multiple dimensions of interdependence influenced actors' trust towards them in future interactions. To do so, we ran a dyadic linear mixed model similar to the ones reported above. We included actor's trust in their partner at time $t_{0}$ as the outcome variable and mutual dependence, conflict of interests, and relative power, as well as their interactions with partner's cooperation at $t_{0}$, as the predictors. We also included trust at $t_{-1}$ as a predictor, so that the model estimates the effect of interdependence and partner's behavior on (residual) change in trust from before the interaction to after the interaction had occurred (Castro-Schilo \& Grimm, 2018). Again, we used a dual intercept model to estimate random effects separately for each dyad member and allow them to covary.

Actors' perceptions of higher conflict of interests at $t_{0}$ were associated with lower trust in their partner at $t_{0}, \beta=-.05, S E=.01, t(3003.04)=-3.88, p<.001$, whereas actors' perceptions of their partner's behavior at $t_{0}$ as more cooperative were associated with higher trust in their partner at $t_{0}, \beta=.08, S E=.01, t(3098.70)=5.26, p<.001$. In contrast, neither mutual dependence nor relative power had a significant association with trust at $t_{0}$ (Table S9). Importantly, we also observed interactions of partner's cooperation with conflict of interests, $\beta=.04, S E=.01, t(3027.20)=3.12, p=.002$, and with mutual dependence, $\beta=.03, S E=.01$, $t(3024.40)=3.37, p=.001$. The interaction between partner's cooperation and relative power was not significant. Tests of simple slopes at \pm 1 SD of conflict of interests and mutual dependence revealed a stronger positive effect of partners' cooperation on trust at $t_{0}$ when conflict of interests was high, $\beta=.11, S E=.02, t(3063.76)=6.36, p<.001$, rather than low, $\beta=.04, S E=.02, t(3074.78)=2.45, p=.014 ;$ similarly, partners' cooperation was positively associated with trust at $t_{0}$ when mutual dependence was high, $\beta=.12, S E=.02, t(3043.61)=$ $7.16, p<.001$, but not when it was low, $\beta=.04, S E=.02, t(3082.27)=1.71, p=.088$. 
In other words, actors' experience of a conflict of interests with their partner was associated with a small, but significant decrease in trust. However, this was ameliorated when actors perceived that their partner behaved more cooperatively despite the existing conflict of interests. In addition, partners' cooperation had a stronger positive association with trust in situations involving greater mutual dependence. We fully replicated these results with relationship satisfaction as the outcome; for details, see SI. Thus, not only do daily experiences of interdependence shape trust and relationship satisfaction among partners; reacting cooperatively to the challenges of conflicts of interests can make them an opportunity to develop trust and improve relationship outcomes.

Second, we also examined the long-term consequences of everyday experiences of interdependence in close relationships. Experiences of interdependence may accumulate over time to influence attitudes between partners. Specifically, we explored how experiences of mutual dependence, conflict of interests, and relative power in everyday situations related to change in commitment and satisfaction over time. For this purpose, we fitted a manifest covariate model using Mplus 8.3 (Muthén \& Muthén, 2017). We regressed commitment at follow-up (one week after the end of the experience sampling phase) on commitment at intake, as well as the manifest mean score of mutual dependence, conflict of interests, and relative power during the experience sampling phase. In the path model, we estimated paths separately for male and female partners, but constrained paths to be equal. Partners' commitment scores were allowed to covary within each timepoint. In these analyses, we included all situations partners experienced with each other, including those only one partner reported on $(k=6,517$ reports from $n=133$ couples $)$.

Higher mean levels of conflict of interests during the experience sampling phase were associated with lower commitment a week later, $\beta=-.51,95 \% \mathrm{CI}=[-.72,-.33], p<.001$, Table S10. In contrast, average levels of mutual dependence and relative power did not 
significantly relate to commitment. This means that individuals who experienced, on average, greater conflict of interests with their partner in everyday situations showed a significant decrease in commitment to their relationship even a week later. Results show a similar effect for relationship satisfaction and are robust when including interactions between each dimension of interdependence and partners' behavior (see SI).

\section{Study 2: Interdependence in Daily Life - Individuals}

Study 1 focused on describing the patterns of interdependent interactions experienced in daily life by romantic couples and on testing how cooperation varied across interdependent situations. By attending to romantic couples, we were able to acquire two reports on the same situation and found that partners largely agreed about their interdependence and cooperation experienced in those situations. In Study 2, we expand our focus to describe the patterns of interdependent interactions people perceive in situations experienced with any type of interaction partner (e.g., close others, colleagues at work, strangers) and further examine how interdependence varies across interaction partners.

An advantage of experience sampling methods is that participants report on situations soon after experiencing them, therefore reducing recall bias. However, across both our experience sampling studies, participants reported on their interdependence with others after experiencing the outcome of the situation, and experiencing the outcome of the situation could have influenced how they reported their interdependence. To address this issue, in Study 2, we also had participants interact in economic games commonly used to study cooperation. There, participants reported on their perceived interdependence, prior to experiencing any feedback about the outcome of the interaction. We can use these reports to understand if the same relations hold for perceptions of interdependence and cooperation in a controlled laboratory setting and in daily life. Additionally, we can compare reports of interdependence in the laboratory to reports of interdependence experienced in daily life to 
understand whether the majority of daily situations are perceived more or less similar to certain types of experimental lab situations commonly used to study cooperation.

Sample and data collection. We used panel agencies and snowball sampling to acquire a Dutch community sample $\left(n=284,30 \%\right.$ male, $M_{\text {age }}=35.55$ years, $S D=16.02$, range 18 80). We sought to recruit 300 participants, based on financial and practical constraints. The final sample size deviates somewhat due to no-shows of recruited participants. As for Study 1, we did not conduct either a priori or sensitivity power analyses; see SI for details. No analyses were conducted before data collection was completed. All materials, data, and analyses syntax for the study can be found on the OSF (https://osf.io/dwbz3/).

Among participants, $22.9 \%$ had a university education, $42.2 \%$ had completed vocational training, and $33.0 \%$ had completed secondary education. Further, $91.2 \%$ reported being born in the Netherlands. Finally, the reported median monthly net income was $€ 1,000$ 1,199 , and a significant proportion reported monthly net incomes above $€ 2,500$ (10.9\%). Overall, although the sample had more female than male participants, it was heterogeneous in terms of age, education, and income.

Procedure. The procedure was similar to Study 1. Participants were recruited via online panels. During an intake session, they completed personality and attitude surveys and were instructed for the experience sampling phase. Then, they completed a one-week experience sampling phase in which we collected descriptions of daily life situations. Measures not included in the current study are listed on the OSF.

Intake session. In the laboratory, participants first completed individual difference questionnaires and demographic questions (similar to Study 1). After a break, they received detailed instructions for a series of incentivized one-shot economic games, including examples and comprehension questions. Responses were anonymous, and no feedback on payoffs or others' choices was provided. Participants were randomly matched with each other 
after the session. One task was randomly selected to be paid out, and participants could earn a bonus of $0-10$ euros based on their own and the other's decisions. We did not employ deception at any point. This part took approximately 30 minutes to complete.

Finally, participants received detailed instructions about the experience sampling phase. Research assistants read a script and used slides to present and explain all questionnaires included in the experience sampling surveys. The exact text of the instructions can be found on the OSF.

Experience sampling phase. Similar to Study 1, for seven consecutive days, participants received seven messages a day between 08:00 and 22:00. Each link directed participants to a short survey (median time to completion was 2:36 minutes).

Participants were asked whether they had experienced a situation with another person in this period. If so, they were asked to report on the last situation they had experienced with another person (“Social” stream). If not, participants were asked to report on the last situation they experienced before they began filling in the questionnaire ("Nonsocial" stream). In this study, we only analyze data from the "Social" stream.

The overall response rates were $78.6 \%$, and median per-subject response rates were even higher (87.8\%). Overall, we obtained 10,930 responses, and 7,248 responses were in the "Social” stream ("Nonsocial" stream = 3,682).

Participant earnings. Participants were paid 20 euros for participating in the intake session, up to 10 euros based on their own and others' decisions in economic games, 0.50 euros per completed experience sampling survey, and a bonus of 20 euros for responding to at least $75 \%$ of the experience sampling surveys. On average, they earned 60.23 euros $(S D=$ 13.98). 
Figure 2. Economic games used in the laboratory experiment (Study 2).
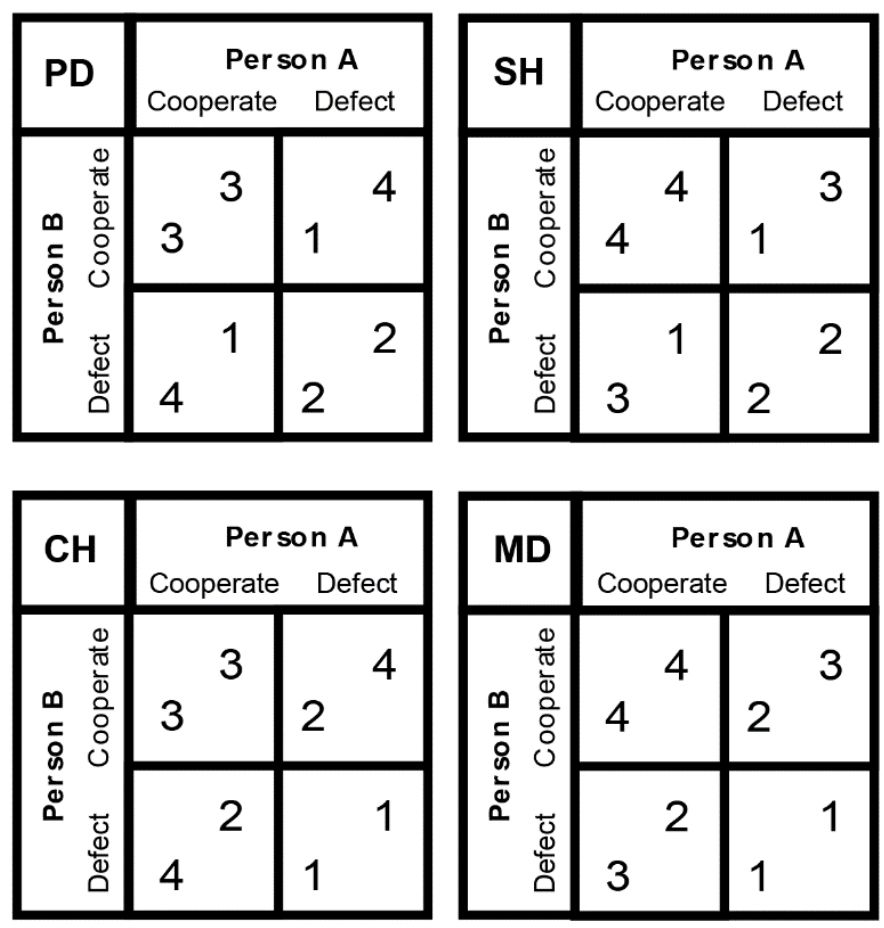

Note: The values in the matrices represent the outcomes for each person depending on both persons' choices. The four games vary in their conflict of interests, which can be calculated as a Correspondence Index varying from -1 (conflict) to +1 (correspondence) (Kelley et al., 2003). The Correspondence Index is -0.80 in the Prisoner's Dilemma (PD), 0.20 in the Stag Hunt $(\mathrm{SH})$ and Chicken $(\mathrm{CH})$ games, and 0.80 in the Maximizing Difference (MD) game.

\section{Measures}

Intake session. During the intake session, participants completed various individual difference measures and experimental tasks irrelevant to the present research (a full list of measures is available on the OSF). Pertinent to the questions examined here, participants made decisions in a series of anonymous, incentivized, one-shot economic games (i.e., a Prisoner's Dilemma, a Stag Hunt game, a Chicken game, and a Maximizing Difference game) (Fig. 2). These games differ in objective conflict of interests, but neither mutual dependence nor relative power. In each game, the participant makes a decision between two choice options, cooperation (labelled 'A') and defection (labelled 'B'). Each participant's decision was matched to the decision of another participant after the end of the session, 
determining their outcome from the game. We randomly selected one game for each participant to be paid out.

After reading the instructions for each game, participants rated their interdependence with the other person using the 10-item version of the SIS (Gerpott et al., 2018). Participants provided these ratings prior to receiving any feedback on the outcomes of the game; thus, experienced outcomes could not influence participants' perceptions of interdependence.

Experience sampling phase. After participants had selected a situation, we asked them to report the nature of their relationship with the other person (i.e., "romantic partner", "family", “friend”, “co-worker", “supervisor", "acquaintance”, and "stranger”), and the place where the situation occurred (e.g. "at home", "at work", etc.). We further asked participants to describe the situation in one to three sentences, focusing on what they did and what the other person did (examples of situations are available in the SI and on the OSF). Then, participants completed the 10-item SIS scale with reference to the other person in the situation they just described. We computed multilevel item correlations accounting for dependence within individuals $(n=276, k=7,167)$. Item correlations for each subscale were mid-sized (95\% confidence intervals for multilevel correlations, mutual dependence: $r=[.32$, $.36]$, conflict of interests: $r=[.44, .48]$, relative power: $r=[.63, .66])$. We also calculated how reliably these measures assessed within-person change over time by computing $R_{C}$ (Bolger \& Laurenceau, 2013; Cranford et al., 2006). The reliability of change was acceptable to good (mutual dependence: .51, conflict of interests: .63, relative power: .78); see SI for details.

Finally, participants responded to two questions measuring how beneficial versus costly (a) their own behavior was for the other person (i.e., own cooperation) and (b) the other person's behavior was for themselves (i.e., other's cooperation) (described in Study 1). 


\section{Analyses}

Analyses were performed in R (R Core Team, 2017). Unless otherwise noted, mixed effects models were fitted with REML estimation using the package 'lme4' (Bates, Mächler, Bolker, \& Walker, 2014) and confidence intervals were obtained by profiling, in some cases, bootstrapping. Significance tests on these models were performed using Satterthwaite approximation for degrees of freedom with the package 'ImerTest' (Kuznetsova, Brockhoff, \& Christensen, 2017).

Ns vary between analyses because some participants only completed part of the procedure (e.g., did not complete parts of the intake surveys or dropped out of the experience sampling phase without providing any responses). Analyses of perceived interdependence were run on data from $N=276$ participants reporting $k=7,167$ situations. Analyses of cooperation in daily life were run on data from $N=276$ participants reporting on $k=7,153$ situations.

\section{Results}

We begin by analyzing the patterns of interdependence people experience in daily life, how interdependence varies across interaction partners, and whether each dimension of interdependence has a unique relation with cooperation - and further examining any possible interactions between interdependence dimensions in predicting cooperation. Then, we consider the experimental results and (1) examine whether subjective interdependence varied across games in line with variation in objective interdependence, (2) attempt to replicate the associations between interdependence and cooperation in the games, and (3) compare how people perceived the different games to how they perceived interdependence in daily life.

Interdependence in daily life. We first examine the distributions of participants' perceptions of interdependence along three dimensions using linear mixed models with random factors for subjects. Table 4 displays the variance components of each dimension of 
interdependence. We found that the within-person variance $\sigma^{2}$, which reflects both true variation between situations and measurement error, was larger than the between-subject variance. This implies that perceptions of interdependence vary more between situations than between persons, as would be expected if these reports reflect variation in the structure of experienced situations rather than individual differences in how people think about situations.

Table 4. Variance components of (standardized) mutual dependence, conflict of interests, and relative power at the level of situation and persons (Study 2).

\begin{tabular}{crrr}
\hline Variance & $\begin{array}{c}\text { Mutual } \\
\text { Dependence }\end{array}$ & $\begin{array}{c}\text { Conflict of } \\
\text { Interests }\end{array}$ & $\begin{array}{c}\text { Relative } \\
\text { Power }\end{array}$ \\
\hline Within-person $\sigma^{2}$ & .71 & .77 & .91 \\
Between-person $\tau_{00}^{2}$ & .30 & .20 & .02
\end{tabular}

Note: Within-person variance reflects both true variation between situations and measurement error. $N=276, k=7,167$.

Figure 3. The distribution of situations experienced in daily life along mutual dependence, conflict of interests, and relative power (Study 2).

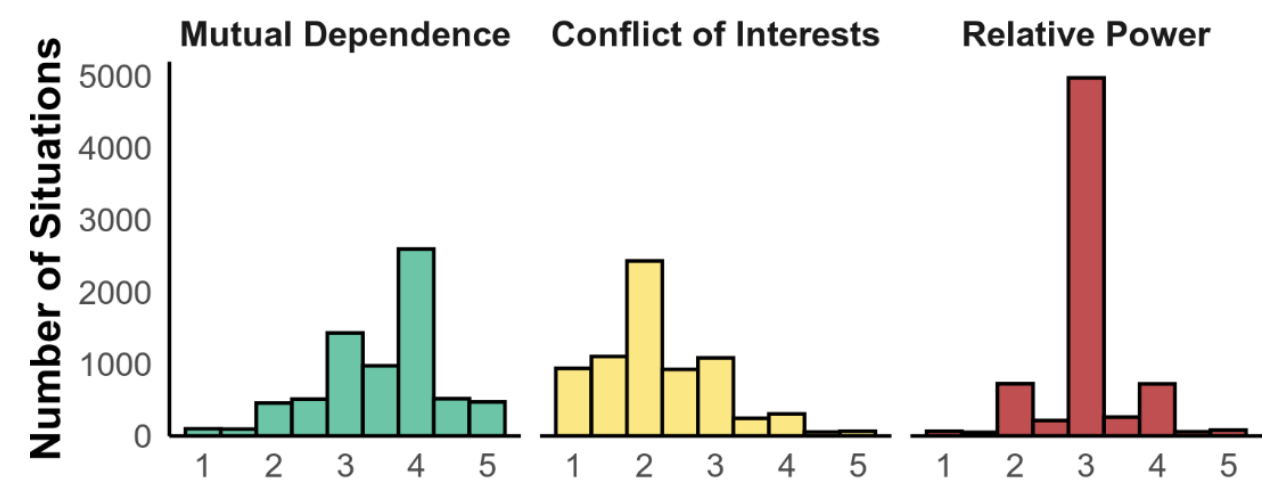

Note: The y-axis shows the total number of situations experienced across all types of interaction partners. The $\mathrm{x}$-axis displays the value on reported mutual dependence $(1=$ independence, $5=$ mutual dependence $)$, conflict of interests $(1=$ corresponding interests, $5=$ conflicting interests) and relative power $(1=$ low, $3=$ equal, $5=$ high $) . N=276, k=7,167$. 
Examining the distribution of situations along each dimension of interdependence, we found that a majority of everyday social situations contained moderate mutual dependence $(M d n=4)$ and corresponding interests $(M d n=2$; Fig. 3). People rarely reported situations with conflicting interests; out of all situations, only $9.45 \%$ were rated above the scale midpoint. Finally, people mostly reported situations involving equal power $(M d n=3) ; 69.4 \%$ were rated at the scale midpoint, indicating that neither person held more power than the other.

Similar to Study 1, we found that the multilevel correlations between the dimensions (accounting for dependence within individuals) were negligible: Mutual dependence had a small positive association with conflict of interests, $r=.04, t(7165)=3.06, p=.002$, and a small negative relation with relative power, $r=-.04, t(7165)=-3.54, p<.001$. Conflict of interests was unrelated to relative power, $r=-.01, t(7165)=-.45, p=.651$.

Therefore, similar to the reports of situations experienced in daily life among romantic couples, we found that perceptions of interdependence varied more across situations than across individuals, and that the majority of situations experienced in daily life involve moderate mutual dependence, largely corresponding interests, and symmetric power.

Interdependence across interaction partners. The nature of interdependent situations may vary systematically depending on who people interact with. We therefore examined how the observed patterns of interdependence perceptions varied across situations experienced with close others, colleagues and supervisors, and strangers. To do so, we looked at the distributions of interdependence perceptions that participants reported in situations with different partners (e.g., romantic partners, supervisors, and strangers).

As displayed in Figure 4, of the total number of reported social situations ( $n=276, k=$ 7,167), we observed a range of interactions with romantic partners (18.5\%), family (20.0\%), friends $(20.0 \%)$, acquaintances $(3.7 \%)$, colleagues (14.6\%), supervisors $(2.3 \%)$, and strangers 
$(10.2 \%)$. We fitted three separate mixed models with random factors for participants and type of interaction partner as a fixed factor predicting mutual dependence, conflict of interests, and relative power. The experience of mutual dependence, conflict of interests, and relative power varied in some ways across different interaction partners (Table 5). The type of interaction partner explained about $1 \%$ of variance in the experience of mutual dependence, conflict of interests, and relative power (see SI). Participants experienced the least mutually dependent outcomes when interacting with strangers, and more mutual dependence when interacting with supervisors than with their partner, family, or friends. Further, interactions with partners and friends involved more corresponding (i.e., less conflicting) interests than situations with colleagues, acquaintances, and strangers. Finally, as would be expected, participants reported having less relative power in situations experienced with their supervisors as compared to all other interaction partners. 
Figure 4. Reported mutual dependence, conflict of interests, and relative power by type of interaction partner (Study 2).

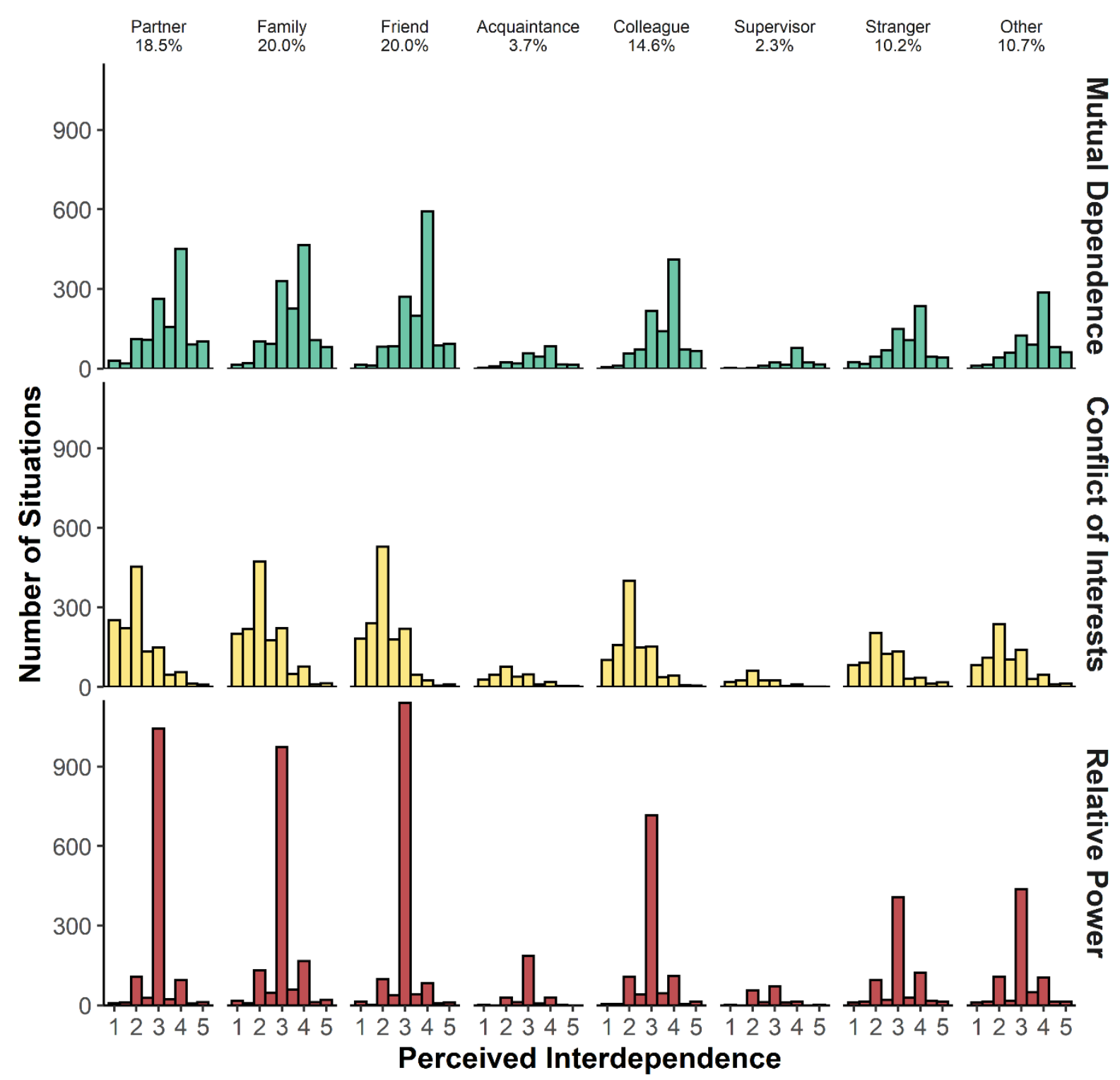

Note: The y-axis shows the total number of situations experienced with each type of interaction partner. The $\mathrm{x}$-axis displays the value on reported mutual dependence $(1=$ independence, $5=$ mutual dependence $)$, conflict of interests $(1=$ corresponding interests, $5=$ conflicting interests) and relative power ( $1=$ low, $3=$ equal, $5=$ high). $N=276, k=7,167$. 
Table 5. Mean differences in mutual dependence, conflict of interests, and relative power in situations with different interaction partners (Study 2).

\begin{tabular}{|c|c|c|c|c|c|c|c|c|}
\hline & Partner & Family & Friend & Acq. & Coll. & Superv. & Stranger & $\begin{array}{c}\text { LS } \\
\text { Means } \\
\end{array}$ \\
\hline Partner & & & & & & & & 3.51 \\
\hline \multirow{6}{*}{ 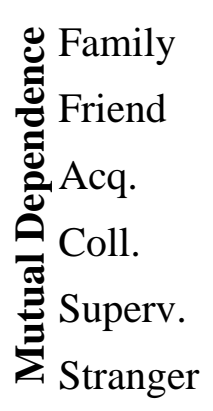 } & -0.01 & & & & & & & 3.49 \\
\hline & 0.01 & 0.02 & & & & & & 3.52 \\
\hline & -0.09 & -0.08 & -0.10 & & & & & 3.42 \\
\hline & 0.07 & 0.08 & 0.06 & $0.16^{*}$ & & & & 3.58 \\
\hline & $0.21 *$ & $0.22 *$ & $0.20^{*}$ & $0.30^{*}$ & 0.14 & & & 3.72 \\
\hline & $-0.14 *$ & $-0.13 *$ & $-0.15^{*}$ & -0.05 & $-0.21 *$ & $-0.35^{*}$ & & 3.36 \\
\hline Other & 0.09 & 0.10 & 0.08 & $0.18 *$ & 0.02 & -0.12 & $0.23 *$ & 3.60 \\
\hline \multirow{7}{*}{ 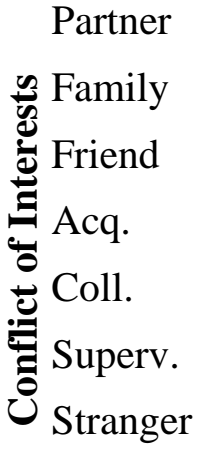 } & & & & & & & & 2.10 \\
\hline & 0.09 & & & & & & & 2.19 \\
\hline & 0.02 & -0.07 & & & & & & 2.13 \\
\hline & $0.23^{*}$ & 0.14 & $0.21 *$ & & & & & 2.33 \\
\hline & $0.14^{*}$ & 0.05 & $0.12 *$ & -0.09 & & & & 2.24 \\
\hline & 0.17 & 0.08 & 0.15 & -0.06 & 0.03 & & & 2.27 \\
\hline & $0.31 *$ & $0.22 *$ & $0.29 *$ & 0.08 & $0.17 *$ & 0.14 & & 2.41 \\
\hline Other & $0.19 *$ & 0.10 & $0.16^{*}$ & -0.04 & 0.05 & 0.02 & $-0.12^{*}$ & 2.29 \\
\hline Partner & & & & & & & & 2.99 \\
\hline Family & 0.04 & & & & & & & 3.04 \\
\hline Friend & -0.01 & -0.05 & & & & & & 2.99 \\
\hline$\underset{0}{0}$ Acq. & -0.02 & -0.06 & -0.01 & & & & & 2.98 \\
\hline Coll. & 0.03 & -0.02 & 0.03 & 0.05 & & & & 3.02 \\
\hline Superv. & $-0.26^{*}$ & $-0.30 *$ & $-0.25^{*}$ & $-0.24 \&$ & $-0.29 *$ & & & 2.73 \\
\hline Stranger & 0.06 & 0.02 & 0.07 & 0.08 & 0.04 & $0.32 *$ & & 3.06 \\
\hline Other & 0.03 & -0.02 & 0.03 & 0.05 & 0.00 & $0.29 *$ & -0.03 & 3.02 \\
\hline
\end{tabular}

Note: $P$-values are adjusted for multiple comparisons based on Tukey's method for comparing a family of eight estimates. ${ }^{*} p<.05$. Acq. = Acquaintance; Coll. = Colleague; Superv. $=$ Supervisor. $N=276, k=7,167$. 
Cooperation is associated with interdependence in daily life. We found that daily life is filled with cooperative interactions. The predominance of cooperation in daily life was striking; participants rarely reported behaving in a non-cooperative manner (5.33\% of all situations). They also did not report others frequently being non-cooperative ( $7.42 \%$ of all situations). Thus, rates of perceived non-cooperation are similar across both studies, and across reports on own behavior and the behavior of others, which suggests that self-reports of own cooperation are unlikely due to socially desirable responses.

We tested whether variation in perceived mutual dependence, conflict of interests, and relative power is associated with changes in self-reported (a) own and (b) others' cooperation ( $k=7,153$ observations from $n=276$ participants). We used two mixed models with SIS variables as predictors of own and other's cooperation. The models included random intercepts for participants. Further, we used a log-likelihood ratio test to compare the fit of each of these models against a model also including random slopes for each of the three SIS dimensions, and retained the latter model in both cases (own cooperation: $X^{2}(9)=186.08, p<$ .001 ; other's cooperation: $\left.X^{2}(9)=227.52, p<.001\right)$. We report bootstrapped confidence intervals for these models.

Importantly, cooperation was associated with the interdependence structure of the situation (Table 6; Fig. 5). Individuals reported behaving more cooperatively in situations with higher mutual dependence, $\beta=.09, S E=.01, p<.001$, partial $R_{\beta}^{2}=.14$, and more corresponding interests, $\beta=-.28, S E=.02, p<.001$, partial $R_{\beta}^{2}=.55$. This generalized to perceived others' cooperation (Table 6): individuals reported that others were more cooperative in situations with higher mutual dependence, $\beta=.07, S E=.01, p<.001$, partial $R_{\beta}^{2}=.10$, and more corresponding interests, $\beta=-.32, S E=.02, p<.001$, partial $R_{\beta}^{2}=.57$. Relative power was unrelated to own, $\beta=.01, S E=.01, p=.329$, partial $R_{\beta}^{2}<.01$, and others' cooperation, $\beta=.00, S E=.01, p=.763$, partial $R_{\beta}^{2}<.01$. Therefore, we replicated the 
findings from Study 1 that lower conflict of interests was associated with higher cooperation.

Moreover, higher mutual dependence was positively associated with cooperation, whereas

relative power had no relation with reports of own and other's cooperation. Thus,

associations between interdependence and cooperation generalized beyond romantic couples and across many different interaction partners in daily life. ${ }^{3}$

Figure 5. Self-reported cooperation at each level of mutual dependence, conflict of interests, and relative power (Study 2).
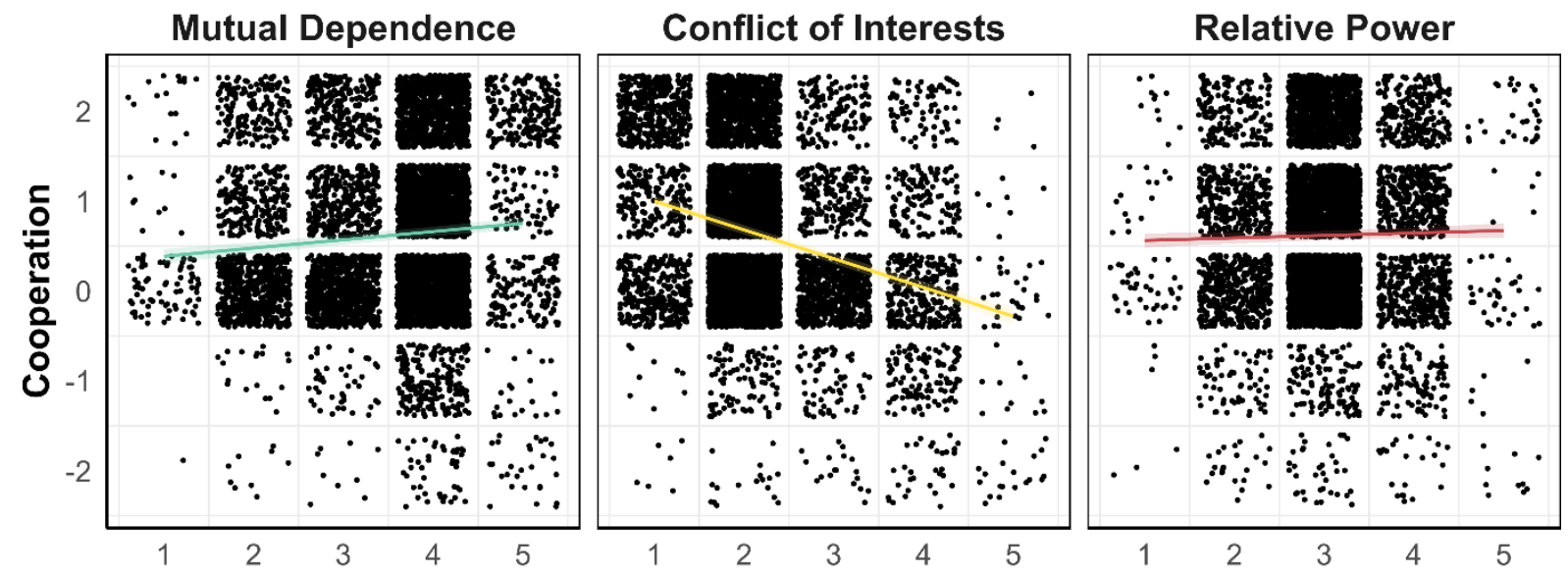

Note: In each panel, a dot indicates one reported situation. 95\% confidence intervals around regression lines show the relationship between cooperation and each dimension of interdependence (see Table 6).

Table 6. Participants' reported mutual dependence, conflict of interests, and relative power predict (a) self-reported own cooperation and (b) self-reported others' cooperation in daily life (Study 2).

\begin{tabular}{|c|c|c|c|c|c|c|c|c|c|c|}
\hline & \multicolumn{5}{|c|}{ Own Cooperation } & \multicolumn{5}{|c|}{ Other's Cooperation } \\
\hline & $\boldsymbol{\beta}$ & $S E$ & $d f$ & $T$ & $p$ & $\boldsymbol{\beta}$ & $S E$ & $d f$ & $t$ & $p$ \\
\hline Intercept & 00 & .03 & & & & .02 & .03 & & & \\
\hline $\begin{array}{l}\text { Mutual } \\
\text { Dependence }\end{array}$ & .09 & .01 & 244 & 6.18 & $<.001$ & .07 & .01 & 216 & 4.82 & $<.001$ \\
\hline $\begin{array}{l}\text { Conflict of } \\
\text { Interests }\end{array}$ & -.28 & .02 & 229 & -16.58 & $<.001$ & -.32 & .02 & 237 & -17.57 & $<.001$ \\
\hline $\begin{array}{l}\text { Relative } \\
\text { Power }\end{array}$ & .01 & .01 & 197 & .98 & .329 & .00 & .01 & 169 & .30 & .763 \\
\hline
\end{tabular}


To assess whether interactions between dimensions of interdependence explained

further variance in cooperation, we fitted additional models that also included all interaction

terms as fixed effects. We compared these against the main-effects-only models using log

4

likelihood ratio tests. For both self-reported own, $X^{2}(4)=49.41, p<.001, \Delta R^{2}=.01$, and other's cooperation, $X^{2}(4)=93.21, p<.001, \Delta R^{2}=.01$, the interaction terms explained about $1 \%$ of additional variance.

For both dependent variables, mutual dependence was positively associated with cooperation, while conflict of interests showed a negative relationship. The effect of conflict of interests was further moderated by two two-way and a three-way interaction with mutual dependence and conflict of interests. To follow-up the two-way interactions between conflict of interests and the other two dimensions of interdependence, we used simple slope analyses.

We tested the effect of conflict of interests on own and other's cooperation at \pm 1 SD of mutual dependence and relative power. Conflict of interests was more strongly, negatively associated with own and others' cooperation when mutual dependence was high (own cooperation: $\beta=-$ $.32, S E=.02, t=-17.14, p<.001$; other's cooperation: $\beta=-.38, S E=.02, t=-19.30, p<$ .001 ) rather than low (own cooperation: $\beta=-.23, S E=.02, t=-11.37, p<.001$; other's cooperation: $\beta=-.25, S E=.02, t=-11.87, p<.001$; Fig. S2).

Similarly, conflict of interests was more strongly negatively associated with actors' and partners' cooperation when the actor held higher relative power (own cooperation: $\beta=-.35$, $S E=.02, t=-16.81, p<.001$; other's cooperation: $\beta=-.25, S E=.02, t=-12.91, p<.001$ ) rather than lower relative power (own cooperation: $\beta=-.24, S E=.02, t=-12.27, p<.001$; other's cooperation: $\beta=-.37, S E=.02, t=-18.79, p<.001$, Fig. S2).

We exploratorily probed the three-way interactions by applying the same JohnsonNeyman technique to the interaction between conflict of interests and relative power and at low and high levels $( \pm \mathrm{SD})$ of mutual dependence. These analyses show that power 
exacerbated the negative effect of conflict of interests more strongly at high levels of mutual dependence (see SI for details). Overall, these results replicate the findings from Study 1:

Conflict has a negative association with cooperative behavior which is exacerbated at higher levels of mutual dependence and when the actor holds more power relative to their interaction partner. The effect of conflict of interests on cooperation is most negative for actors with high relative power in highly mutually dependent situations.

Table 7. Cooperation rates and average ratings of mutual dependence, conflict of interests, and relative power in four experimental games. Standard deviations in parentheses. P-values are adjusted for multiple comparisons based on Tukey's method for comparing a family of four estimates.

\begin{tabular}{lcccc}
\hline Game & $\begin{array}{c}\text { Cooperation } \\
\text { Rate }\end{array}$ & $\begin{array}{c}\text { Mutual } \\
\text { Dependence }\end{array}$ & $\begin{array}{c}\text { Conflict } \\
\text { of Interests }\end{array}$ & $\begin{array}{c}\text { Relative } \\
\text { Power }\end{array}$ \\
\hline PD & $56.1 \%$ & $3.91(0.89)$ & $3.23(0.99)$ & $3.03(0.48)$ \\
CH & $78.9 \%$ & $3.98(0.86)$ & $3.20(0.94)$ & $3.05(0.46)$ \\
SH & $81.8 \%$ & $3.98(0.85)$ & $2.25(1.07)$ & $3.02(0.46)$ \\
MD & $89.3 \%$ & $3.99(0.82)$ & $2.12(1.05)$ & $3.05(0.49)$ \\
\hline
\end{tabular}

36 Note: $\mathrm{PD}=$ Prisoner's Dilemma; $\mathrm{CH}=$ Chicken game; $\mathrm{SH}=\mathrm{Stag}$ Hunt; $\mathrm{MD}=$ Maximizing 37 Difference game.

39 Table 8. Pairwise comparisons between four experimental games on perceived 40 interdependence and cooperation rate. P-values are adjusted for multiple comparisons based 41 on Tukey's method for comparing a family of four estimates.

\begin{tabular}{|c|c|c|c|c|c|c|c|c|c|c|c|}
\hline \multirow[b]{2}{*}{ Contrast } & \multicolumn{3}{|c|}{ Mutual Dependence } & \multicolumn{3}{|c|}{ Conflict of Interests } & \multicolumn{3}{|c|}{ Relative Power } & \multicolumn{2}{|c|}{ Cooperation } \\
\hline & $d f$ & $t$ & $p$ & $d f$ & $t$ & $p$ & $d f$ & $t$ & $p$ & $Z$ & $p$ \\
\hline $\mathrm{CH}-\mathrm{MD}$ & 803.47 & -0.08 & 1.000 & 813.32 & 13.65 & $<.001$ & 811.40 & -0.04 & 1.000 & -3.43 & .003 \\
\hline $\mathrm{CH}-\mathrm{PD}$ & 804.18 & 1.16 & .655 & 814.49 & -0.39 & .980 & 812.15 & 0.55 & .946 & 6.07 & $<.001$ \\
\hline $\mathrm{CH}-\mathrm{SH}$ & 802.18 & -0.20 & .997 & 811.56 & 12.19 & $<.001$ & 808.21 & 0.6 & .915 & -0.94 & .786 \\
\hline MD - PD & 801.51 & 1.24 & .604 & 810.15 & -14.06 & $<.001$ & 807.52 & 0.60 & .933 & 8.51 & $<.001$ \\
\hline $\mathrm{MD}-\mathrm{SH}$ & 801.31 & -0.13 & .999 & 809.93 & -1.53 & .423 & 806.72 & 0.70 & .899 & 2.57 & .050 \\
\hline $\mathrm{PD}-\mathrm{SH}$ & 801.12 & -1.37 & .520 & 809.75 & 12.60 & $<.001$ & 805.93 & -0.10 & 1.000 & -6.85 & $<.001$ \\
\hline
\end{tabular}

42 Note: $\mathrm{PD}=$ Prisoner's Dilemma; $\mathrm{CH}=$ Chicken game; $\mathrm{SH}=\mathrm{Stag}$ Hunt; $\mathrm{MD}=$ Maximizing 43 Difference game. 
Replication in the lab. Across two studies, we showed consistent links between perceptions of interdependence and self-reported own and others' cooperation (Study 1 and 2) and partner-reports of own and other's cooperative behavior (Study 1). We aimed to replicate these relations in a more controlled environment, where participants reported their perceptions of interdependence prior to experiencing the outcome of an interaction.

Moreover, we have posited that perceptions of interdependence reflect, at least to some degree, actual interdependence. Thus, perceptions of interdependence should track indices of objective interdependence when objective information is available, as in the laboratory. Using four economic games that differ in objective conflict of interests, but not mutual dependence or relative power, we tested whether participants' perceptions of interdependence (a) tracked objective properties of the situation and (b) predicted cooperative behavior. To test whether perceptions of interdependence track objective differences in interdependence, we analyzed participants' ratings of four matrix games. The Prisoner's Dilemma, Chicken Game, Stag Hunt, and Maximizing Differences Game differ in the degree of conflict of interests (index of correspondence; $\mathrm{PD}=-.80, \mathrm{CH}=.20, \mathrm{SH}=.20, \mathrm{MD}=.80$ ). In contrast, the games do not differ in objective mutual dependence or relative power. To test whether games differed in perceived interdependence, we ran three linear mixed models predicting mutual dependence, conflict of interests, and relative power from type of game, with random intercepts for subjects.

Participants reported similar degrees of mutual dependence in all four games $(M \mathrm{~s}=$ 3.91 to 3.99; ANOVA: $F(3,802.29)=.80, p=.495, R_{\beta}^{2}<.01$; Tables 7-8) and correctly recognized them as containing equal power $(M \mathrm{~s}=3.02$ to 3.05 ; $\mathrm{ANOVA}: F(3,808.65)=.263$, $\left.p=.852, R_{\beta}^{2}<.01\right)$. Importantly, they also described the Maximizing Difference $(M=2.12)$ and Stag Hunt $(M=2.25)$ games as containing more corresponding interests than the Chicken game $(M=3.20)$ and the Prisoner's Dilemma $(M=3.23$; ANOVA: $F(3,811.52)=115.62, p<$ 
$.001, R_{\beta}^{2}=.30$ ). Participants' ratings thus track objective conflict of interests. The large difference between the Chicken Game and the Stag Hunt, however, suggests that perceptions of conflict of interests are informed more strongly by cues to possible exploitation (which are present in the Chicken Game, but not in the Stag Hunt) rather than by cues to possible distrust (which are present in the Stag Hunt, but not in the Chicken Game, Coombs, 1973; Hilbig, Kieslich, Henninger, Thielmann, \& Zettler, 2018).

To examine differences in cooperation across the games, we entered cooperation rates as the outcome in a binomial logit mixed model with game as predictor and random intercepts for subjects and computed pairwise comparisons $(n=281$; Table 8$)$. We observed the highest cooperation rates in the Maximizing Difference game (89.3\%), followed by the Stag Hunt (82\%) and the Chicken game (78.9\%; cooperation in the Stag Hunt and Chicken game did not differ statistically), with the lowest cooperation rates in the Prisoner's Dilemma (56\%; Tables 7-8).

Focusing on the two games that have received the most attention in previous theory and research, and which vary in conflict of interests (i.e., the Prisoner's Dilemma contains greater conflict of interests than the Stag Hunt), we tested whether perceptions of conflict of interests mediated the differences in cooperation between these two games. We ran a causal mediation analysis using the R package 'mediation' (Tingley, Yamamoto, Hirose, Keele, \& Imai, 2014), entering game as the treatment variable, the SIS rating of conflict of interests as the mediator, and cooperation as outcome variable; both models included random intercepts for participants. Cooperation was predicted using a binomial logit mixed model. Indeed, the effect of the different games on cooperation was partly mediated by participants' selfreported degree of conflict of interests in these situations. The average causal mediation effect was positive, $\beta=.12,95 \% \mathrm{CI}=[.08, .16], p<.001$, and explained $43.95 \%$ of the total effect $(95 \% \mathrm{CI}=[.29, .64])$. Thus, perceptions of one dimension of interdependence- 
conflict of interests - mediated the relation between objective properties of different situations and variation in cooperative behavior.

Finally, we test the effect of perceptions of interdependence on cooperative behavior across all four games. To disentangle differences in perceived interdependence between games from individual dispositions, we person mean-centered perceptions of mutual dependence, conflict of interests, and relative power. We ran a binomial logit mixed model with cooperation as outcome, the person mean-centered perceptions of interdependence and participants' means across games as predictors, and random intercepts for subjects and games. As expected, within-person differences in perceived conflict of interests were negatively associated with cooperation, $\beta=-.43, S E=.10, Z=4.14, p<.001$, OR $=.65$. In contrast, cooperation did not relate to within-person differences in mutual dependence, $\beta=$ $.07, S E=.09, Z=-.76, p=.447, \mathrm{OR}=.94$, and relative power, $\beta=-.13, S E=.08, Z=-1.63$, $p=.103, \mathrm{OR}=.88$. Moreover, between-person differences in conflict of interests were negatively associated with cooperation, $\beta=-.76, S E=.11, Z=-6.89, p<.001, \mathrm{OR}=.47$, whereas perceived differences in mutual dependence were positively associated with cooperation, $\beta=.37, S E=.10, Z=3.49, p<.001$, $\mathrm{OR}=1.44$. Between-person differences in perceived relative power did not relate to cooperation, $\beta=-.16, S E=.10, Z=-1.66, p=.097$, $\mathrm{OR}=.85$. These patterns replicate our findings from experience sampling: both withinperson and between-person differences in perceived conflict relate negatively to cooperative behavior, with a combined medium-sized effect. Moreover, between-person differences in perceived mutual dependence, but not power-both of which did not differ objectively between games — had a small positive effect on cooperative behavior. 
Figure 6. Frequency of interdependent situations in daily life along three dimensions (Study 2).

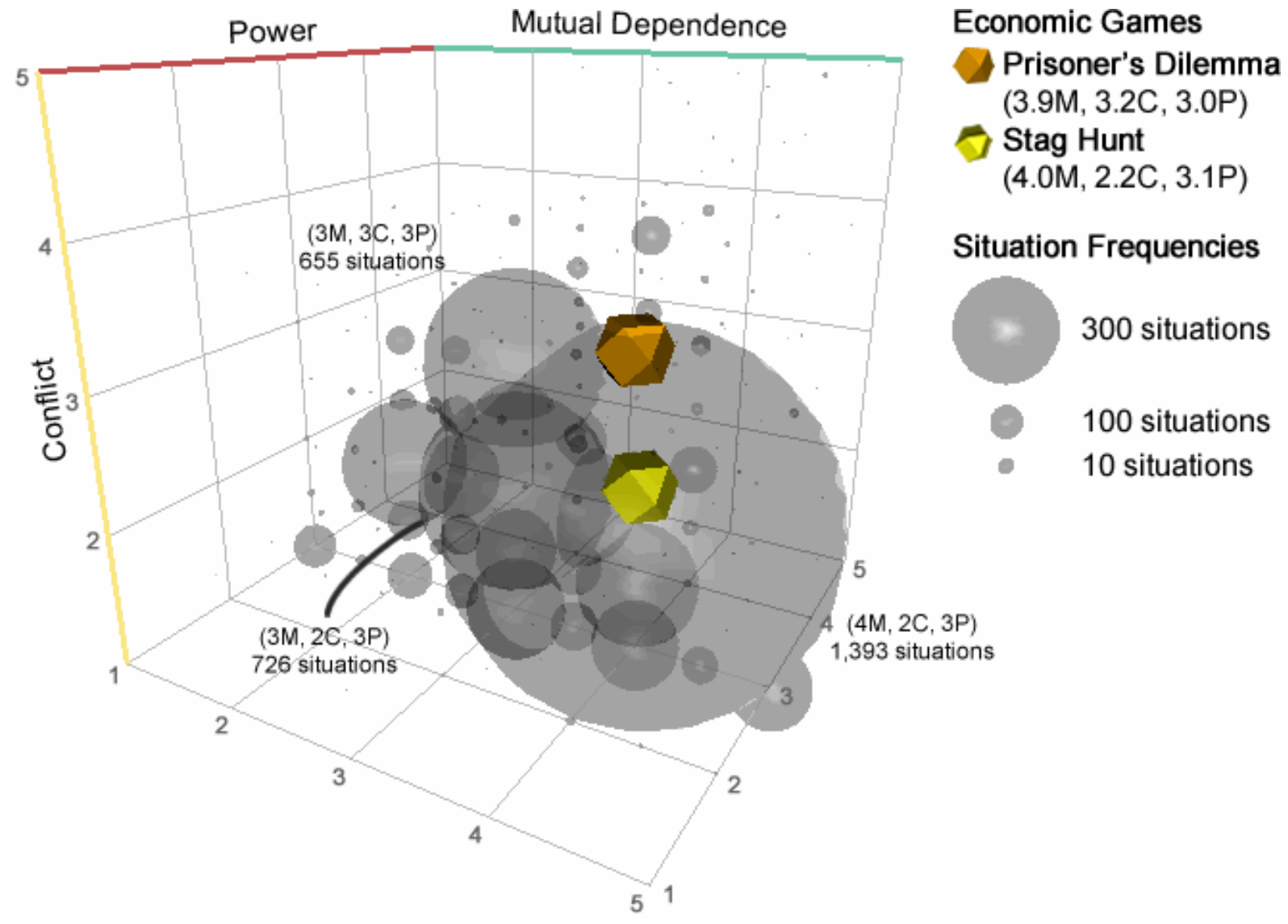

Note: For selected situations, coordinates indicate mutual dependence (M), conflict of interests $(\mathrm{C})$, and relative power $(\mathrm{P})$ on a five-point scale $(1=$ low, $5=$ high $)$. The size of each bubble indicates the frequency of situations in daily life at this coordinate $(1 \leqslant \mathrm{k} \leqslant 1,393)$. Two markers indicate the average perceived interdependence in the Prisoner's Dilemma (orange) and the Stag Hunt (yellow) in laboratory experiments. Coordinates of the Chicken and Maximizing Differences games are not shown as they closely overlap with those of the Prisoner's Dilemma and Stag Hunt, respectively.

Perception of games and daily life situations. Economic games commonly used to study cooperation only cover part of the full space of situations people report experiencing in daily life. Figure 6 displays the frequency of everyday situations along the three dimensions of interdependence. Also shown are the coordinates of the mean ratings of how people experienced the Prisoner's Dilemma and the Stag Hunt. It is striking that the most commonly reported situation — medium to high mutual dependence, mostly corresponding interests, and 
equal power — was perceived very similarly to the average rating of the Stag Hunt. However, large parts of the map are not covered by any of the four matrix games we have considered. For example, relatively little attention has been paid to situations involving corresponding interests, limited mutual dependence, and asymmetrical dependence (i.e., power differences). Most importantly, however, no single game accurately represents the variety of different situations people experience in daily life.

\section{Discussion}

Interdependence underlies all human social interactions. Indeed, theoretical accounts from across the social sciences propose that the form of interdependence in any interaction can influence the behaviors that occur within it (Aktipis et al., 2018; Camerer, 2003; Kelley et al., 2003). Yet, although philosophers and scientists have long theorized about the patterns of interdependence that best characterize human social interactions (Hobbes, 1651/2013; Kelley et al., 2003; Rousseau, 1754/2004; Tomasello et al., 2012), no previous research has attempted to describe this variability in interdependence and its implications for cooperative behavior in daily life. Here, we used a multidimensional measure of how people think about interdependence in social interactions, in combination with experience sampling techniques, to map the interdependent situations that people experience in their everyday lives. In so doing, we were able to describe patterns of interdependence in daily life situations within romantic couples (Study 1) and with any type of interaction partner (Study 2), and examine how cooperation and relationship outcomes (i.e., trust, satisfaction, and commitment) vary along interdependence dimensions.

\section{Prevalent Patterns of Interdependence in Daily Life and in the Lab}

We found that people experience a great variety of interdependent situations in their daily lives. Yet, it is also remarkable that most social interactions involved moderately high mutual dependence, corresponding interests, and equal power. Plotting the reported 
interdependent situations in a three-dimensional space, we found that the most common situation experienced in daily life involved medium to high mutual dependence, corresponding interests, and equal power. Indeed, less than 10 percent of all reported interactions were thought to contain highly conflicting interests. This pattern of interdependence largely generalized across social interactions with close others, organizational members, and strangers.

Further, comparing perceptions of daily life situations experienced with strangers to perceptions of Prisoner's Dilemma and Stag Hunt games played in the laboratory with strangers, we found that the most common ratings of daily interdependence were very similar to rated interdependence in the Stag Hunt (i.e., a game with relatively corresponding interests). This pattern provides some initial evidence that the perceived structure of daily interdependent interactions more closely resembles games of coordination-like the Stag Hunt - rather than social dilemmas_-like the Prisoner's Dilemma. That said, our measures of interdependence in daily life do not allow us to infer the actual strategic properties of experienced situations - i.e., whether people experienced a Stag Hunt, Prisoner's Dilemma, or other interdependence structure. It is possible that participants were experiencing interdependence structures more similar to a Prisoner's Dilemma than a Stag Hunt (i.e., situations objectively containing more conflict of interests), but then construed them as containing less conflict of interests, e.g., because they (a) value the welfare of others (de Dreu \& Carnevale, 2003; Kelley \& Thibaut, 1978; Visserman, Righetti, Muise, Impett, Joel, \& van Lange, 2020), (b) anticipate future interactions (Delton, Krasnow, Cosmides, \& Tooby, 2011; van Lange, Klapwijk, \& van Munster, 2011), (c) expect others to cooperate (Yamagishi, 2011), or (d) perceive that institutions incentivize cooperation (Balliet, Mulder, \& van Lange, 2011). 
Taken together, though, our findings from daily life and lab settings have clear implications for existing theoretical perspectives on the prevalence of interdependence dimensions in daily social interactions. Daily life experiences reported in our samples are more in tune with a Rousseauian world view, which paints human interactions as a Stag Hunt that is conducive to cooperation. Thus, one message from our data is that future work can pay increased attention to situations that are perceived to contain more corresponding interests, similar to the Stag Hunt. Importantly though, no single game could adequately capture the variety of perceived interdependence in daily life, and so the social and behavioral sciences should consider a greater diversity of interdependent situations in the study of social behavior.

An important advantage in documenting the interdependent situations people experience in daily life is that this knowledge offers insight into the psychological processes which produce behavior (Kelley et al., 2003; Reis, 2008). To illustrate, situations that are perceived to contain a conflict of interests produce a motivational problem for cooperation (i.e., weighting own and others' outcomes), while corresponding interests situations pose an epistemological problem for cooperation (e.g., having common knowledge about how to achieve mutual gain; Thomas et al., 2014). Our findings suggest that, to the extent that people perceive most social interactions as containing corresponding interests, interventions that improve common knowledge may be more efficient in promoting cooperation, compared to interventions that aim to boost people's prosocial motivations.

\section{Agreement and Accuracy in Perceived Interdependence}

Our studies also provide evidence that people align in their perception of everyday situations. When romantic couples reported on the same situation, partners strongly agreed on the overall pattern of mutual dependence, conflict of interests, and relative power in that situation, although agreement on individual dimensions was slightly lower than typically 
observed for evaluations of more long-term relationship qualities (Brackett et al., 2005; Pierce et al., 1997; Saffrey et al., 2003). This supports the idea that people can use cues in a situation to make inferences about an underlying shared reality (Balliet et al., 2017). These findings also fit with previous research that has found substantial overlap in how people construe a situation from within that situation and how third-party observers construe the same situation (Gerpott et al., 2018; Rauthmann, 2012; Rauthmann \& Sherman, 2019; Rauthmann, Sherman, Nave, \& Funder, 2015). That said, perceptions of situations may also align because partners have similar personality (Gonzaga, Campos, \& Bradbury, 2007) and/or because they communicate and mutually influence each other. Future research may thus study whether dyads of different relationship types (e.g., attachment styles, asymmetrical power) differ in their agreement in construal of situations and test how the extent of agreement can affect relationship outcomes.

Study 2 further corroborates the proposition that agreement in the construal of an interdependent situation reflects rootedness of perception in a shared reality. People were largely able to distinguish the experimental games according to their degree of conflict of interests, and recognized that the games did not vary in objective mutual dependence and relative power. Thus, emerging evidence from the present study and past research suggests that perceptions of interdependence reflect, to a considerable degree, the actual interdependence people experience together in a situation (though this does not rule out a role for personality, Funder, 2016; Gerpott et al., 2018; Rauthmann, Sherman, \& Funder, 2015). Importantly, the types of objective information provided in experimental studies are often lacking in daily life situations. Future research may examine the non-verbal and verbal cues that people use in these daily social interactions to infer mutual dependence, conflict of interests, and relative power. 


\section{Interdependence Relates to Cooperation in Daily Life}

Findings from our studies further illustrate the value of a multidimensional approach to measuring how people think about their interdependence, by showing that (a) perceptions of interdependence across different dimensions have unique relations with cooperation and (b) interactions between dimensions explain additional variance in cooperative behaviors.

Previous theory suggests that people should be more cooperative when they have a stake in the other's welfare and when they depend on each other to acquire benefits (Aktipis et al., 2018; Balliet et al., 2017; Roberts, 2005). Across various models in our studies with couples and individuals (though see p. 26 for one exception), we see that when people perceive a situation to contain more mutual dependence, they report engaging in behaviors that are more beneficial to others in that interaction (and they similarly report others engaging in more other-benefiting behaviors). However, effects of mutual dependence on own and others' cooperation are small throughout our analyses. That said, while previous findings associating mutual dependence with cooperation could have been interpreted as due to higher mutual dependence leading to lower conflict of interests, our data suggests that (a) mutual dependence and conflict of interests are only weakly associated $(r s=.08, .04$, for Study 1 and 2 , respectively), and (b) mutual dependence positively relates to cooperation after controlling for conflict of interests.

Another benefit of using a multidimensional model of interdependence is that we could compare the relative strength of associations between interdependence dimensions and daily cooperation. We observed that conflict of interests, compared to the other dimensions, had the strongest relation with cooperation. Indeed, much past research has focused on how manipulating the degree of conflict of interests in a situation affects when people cooperate, such as in social dilemmas (de Dreu, 2010; Komorita \& Parks, 1995). Here, we observe that perceptions of conflict of interests across a broad swath of daily life situations relate to when 
people decide to engage in behaviors that benefit others. Future research can test theory that perceived conflict of interests can affect the strategies people deploy to cooperate with others, such as who to select as a cooperative partner, when to cooperate on first encounter, when to avoid interactions or exit relationships, and how strongly to punish a non-cooperative interaction partner (Balliet et al., 2017).

Based on previous research on the effects of power on cooperation in social dilemmas (e.g., de Cremer \& van Dijk, 2005; see Nieper et al., 2019), we expected that powerful individuals would be less cooperative than their lower-power counterparts in daily life interactions. However, we did not find support for this prediction, which could be for multiple reasons. First, we focused on how people think about their interdependence in a specific interaction, and not their relationship in general. People can evaluate a relationship as containing a power difference, but then experience situations that substantially vary with regards to power asymmetry within that same relationship. Indeed, existing research in close relationships (Cross, Overall, Low, \& McNulty, 2019; Righetti et al., 2015; for a review, see Kim, Visserman, \& Impett, 2019), work settings (Fast \& Chen, 2009), and a variety of daily life interactions (Smith \& Hofmann, 2016) suggests that both situational and relationship power have important consequences for interpersonal behaviors, such as the desire to interact with others and the tendency to behave aggressively. Future work should consider the interplay of relational and situational power in affecting cooperative behaviors in daily life (Overall et al., 2016).

Second, our study examined the overall relation between power and cooperation but did not consider potential moderating factors of this relation. Future research can attempt to explain the differences observed between past experiments on power and cooperation and the current experience sampling results, by studying moderators such as (a) the presence of conflict of interests, which is a common feature of experimental tasks but is rare in daily life; 
273

274

275

276

277

278

279

280

281

282

283

284

285

286

287

288

289

290

291

292

293

294

295

296

297

(b) individual differences in social value orientations and self- versus other-focus (Chen, LeeChai, \& Bargh, 2001; Côté et al., 2011; Gordon \& Chen, 2013), which have previously been shown to affect the relations of relative power with empathy, perspective-taking, and cooperation; and, relatedly, (c) the construal of power as autonomy versus responsibility, which may vary across individuals and societies, and can have opposing effects on cooperation (Handgraaf, van Dijk, Vermunt, Wilke, \& de Dreu, 2008; Kopelman, 2009; Smith \& Hofmann, 2016; see Foulk, Chighizola, \& Chen, 2020).

Indeed, our exploratory analyses testing how interactions between multiple interdependence dimensions relate to everyday cooperation support some of the speculations above. Specifically, findings suggest that relative power exacerbates the negative effect of conflict of interests on cooperation. This is consistent with recent models which suggest that the co-presence of power asymmetries and resource threats can be particularly harmful for team outcomes (Greer et al., 2017; cf. Hauser, Hilbe, Chatterjee, \& Nowak, 2019; Ronay et al., 2012). Additionally, our findings suggest that, while situations of mutual dependence might be generally conducive to cooperation, perceived mutual dependence can also exacerbate the negative link between conflict of interests and cooperation. Although the effects of these interactions were small, future studies may examine the interplay between different dimensions of perceived and objective interdependence under more controlled settings.

\section{The Impact of Everyday Diagnostic Situations}

The method we have employed here primarily allowed us to examine the frequency of different interdependent situations in daily life and assess how specific patterns of interdependence relate to cooperation within the same situation. Interdependent situations that are less frequent can nevertheless have an important impact on current and future outcomes. For example, while corresponding-interests situations seem to be more common in 
the daily interactions of our participants, the few severe conflicts of interests experienced could have more important consequences on their lives. We addressed this issue in a pilot study by asking participants to rate the importance of situations in their daily lives, along with their perceptions of interdependence, and found that importance was positively related to perceived mutual dependence but was unrelated to conflict of interests or relative power (see SI). Thus, it is unlikely that the effects we observe can simply be explained by variation in the subjective importance of situations.

Everyday situations allow for the expression of personality traits, and thus carry diagnostic potential. For example, situations involving high conflict of interests afford the expression of personality traits that are linked to concerns for others' well-being (e.g., Honest-Humility, Social Value Orientation; see Thielmann et al., 2020). Our results indicate that people consider the degree of conflict of interests when evaluating their partner's behavior. We found that, although experiencing conflict of interests led people to show less trust in their partner, this was ameliorated when their partner behaved cooperatively. This suggests that people infer trustworthiness from cooperative behavior especially when the situation would have afforded exploitation. Put differently, these results also entail that experiencing corresponding interests typically relates to more trust towards one's partner, but this positive outcome is diminished when one's partner behaves uncooperatively. Interdependence further holds implications for understanding key affordances that might strengthen or weaken links between personality traits and cooperation (see Galinsky et al., 2015; Holmes, 2002; Kelley et al., 2003; Reis, 2008; Rusbult \& van Lange, 2003). In high conflict-of-interests situations, individual differences in the weight people assign to their own and others' outcomes strongly relate to decisions to cooperate (Hilbig et al., 2018; Thielmann et al., 2020; but see Columbus, Thielmann, \& Balliet, 2019), but such individual differences matter much less when there is less conflict of interests (i.e., there exist high individual 
benefits from cooperation). Instead, situations that contain little conflict of interests may afford the expression of dark personality traits (e.g., Machiavellianism) in cooperative decisions. In fact, a recent meta-analysis has found that Machiavellianism and trait Competitiveness had a stronger negative relation with cooperative decisions in situations that contain lesser, compared to greater, conflict of interests (Thielmann et al., 2020).

The patterns of interdependence people experience in everyday situations also have cumulative effects on their attitudes. Here, we found that higher mean levels of conflict of interests in everyday life predicted a reduction in people's commitment to their partner over time and in their subsequent relationship satisfaction. This indicates that people change their attitudes towards close others partly in response to the kinds of situations they experience together. Together, these findings indicate that beyond allowing for inferences about others' character, the patterns of interdependence people experience can themselves shape relationship outcomes.

\section{Future Directions: Ecology, Interdependence, and Culture}

Our study relied on two large, community samples of individuals and romantic couples, recruited in the Netherlands. These participants most frequently reported a pattern of moderate to high mutual dependence, corresponding interests, and equal power in their daily social interactions. Such experiences are in tune with a Rousseauian world view, which paints human interactions as benign and conducive to cooperation. Indeed, people may actively select situations, choose partners, and enter relationships that promise cooperative interactions (e.g., Barclay \& Willer, 2007). However, the extent to which these patterns of interdependence generalize outside WEIRD (Western, Educated, Industrialized, Rich, and Democratic; Henrich, Heine, \& Norenzayan, 2010) societies remains an empirical question. Social institutions in a modern Western society may shift the incentive structures underlying 
social interactions to produce egalitarian situations with corresponding interests—an idea consistent with Hobbes (1651/2013; Pinker, 2011).

More broadly, daily interdependence could underlie and explain variation in institutions and culture. Specifically, variations across ecologies (e.g., subsistence, environmental hazards, and relational mobility) may lead to different patterns of interdependence that people experience, and cultural differences could emerge, in part, as a functional solution to dealing with specific patterns of interdependence (Berry, 1967; Roos, Gelfand, Nau, \& Lun, 2015; Talhelm et al., 2014). For example, different ecologies can constrain human practices in resource production which, in turn, thrust people into different interdependent situations (e.g., herding produces more conflicting interests than subsistence farming, Nisbett \& Cohen, 1996; rice farming produces more mutual dependence than wheat farming, Talhelm et al., 2014). These local patterns of interdependence can give rise to different norms (e.g., social organization; family versus clans, Henrich, 2014), institutions (e.g., rule of law and government effectiveness, Gächter \& Schulz, 2016), values, and beliefs (Gelfand et al., 2011; Nisbett \& Cohen, 1996; Talhelm et al., 2014). In turn, such norms and institutions can feed back to shift the incentive structures that characterize social interactions (Crawford \& Ostrom, 1995; North, 1991; Powers, van Schaik, \& Lehmann, 2016). The multidimensional model of interdependence reported here, including our method of measuring interdependence in daily life, can be used to understand the variation in situational interdependence across ecologies. This, in turn, can provide an entry for the empirical study of interdependence in daily life as a linchpin of ecology, institutions, and culture.

\section{Conclusion}

We used experience sampling to randomly sample thousands of social situations in the daily lives of two Dutch community samples and had them report their interdependence and cooperation experienced in those situations. We observed a pattern of interdependence in 
daily life situations characterized by mean levels of moderate to high mutual dependence, corresponding interests, and equal power, but also strong variation from situation to situation.

We found that people's perceptions of some of the most commonly studied experimental situations only mapped onto a small fraction of the situations they reported experiencing in daily life. Additionally, we offered several forms of evidence that suggest people's perceptions of interdependence in the experience sampling reports can be used to understand the shared underlying interdependence that people experienced in those situations.

Further, we found abundant amounts of cooperation in daily life. Situations characterized by high mutual dependence and low conflict of interests were associated with greater cooperation, while relative power had no relation with cooperation. Across multiple relationships in which individuals interacted daily, we found that mutual dependence and relative power exacerbated the negative effects of conflict of interests on cooperation. Prevalent patterns of interdependence as well as specific interdependent situations had implications for subsequent relationship outcomes, including trust, relationship satisfaction and commitment.

Researchers' choice to prioritize the study of certain interdependent situations can affect conclusions about cooperation, from how evolution shaped humans to cooperate (Tomasello et al., 2012), to the psychological processes that underlie cooperation (Kelley et al., 2003; Reis, 2008), and the forms of institutions that emerge to regulate cooperation (Snidal, 1985). This is because different interdependent situations can pose unique challenges for cooperation that sometimes call for qualitatively different solutions (Balliet et al., 2017; Camerer, 2003). If scientists prioritize an understanding of social behavior in its natural context, then future research should focus on understanding behavior in situations that map onto what people actually experience. Together, our findings emphasize the need to study cooperation and other social behaviors across a broad diversity of interdependent situations, 
while especially allocating attention to cooperation in situations with more corresponding

398 interests, which are prevalent in daily life.

399 
400

401

402

403

404

405

406

407

408

409

410

411

412

413

414

415

416

417

418

419

420

421

422

423

\section{References}

Adler, D., Murdoch, D., et al. (2019). rgl: 3D Visualization Using OpenGL. [Computer software]. Retrieved from https://CRAN.R-project.org/package=rgl

Aktipis, A., Cronk, L., Alcock, J., Ayers, J. D., Baciu, C., Balliet, D., ... \& Sullivan, D. (2018). Understanding cooperation through fitness interdependence. Nature Human Behaviour, 2(7), 429-431.

Allik, J., de Vries, R. E., \& Realo, A. (2016). Why are moderators of self-other agreement difficult to establish? Journal of Research in Personality, 63, 72-83.

Allport, G. W. (1937). Personality: A psychological interpretation. New York, NY: Holt Rinehart \& Winston.

Asch, S. E. (1959). A perspective on social psychology. In S. Koch (Ed.), Psychology: A study of a science (Vol. 3, pp. 363-383). New York, NY: McGraw-Hill.

Astley, W. G., \& Sachdeva, P. S. (1984). Structural sources of intraorganizational power: A theoretical synthesis. Academy of Management Review, 9(1), 104-113.

Auguie, B. (2017). gridExtra: Miscellaneous Functions for "Grid” Graphics. [Computer software]. Retrieved from https://CRAN.R-project.org/package=gridExtra

Axelrod, R. (1984). The Evolution of Cooperation. New York, NY: Basic Books.

Bache, S. M., \& Wickham, H. (2014). magrittr: A Forward-Pipe Operators for R. [Computer software]. Retrieved from https://CRAN.R-project.org/package=magrittr

Bachrach, D. G., Powell, B. C., Bendoly, E., \& Richey, R. G. (2006). Organizational citizenship behavior and performance evaluations: Exploring the impact of task interdependence. Journal of Applied Psychology, 91(1), 193-201.

Balliet, D., Mulder, L. B., \& van Lange, P. A. (2011). Reward, punishment, and cooperation: a meta-analysis. Psychological Bulletin, 137(4), 594-615. 
Balliet, D., Tybur, J. M., \& van Lange, P. A. (2017). Functional interdependence theory: An evolutionary account of social situations. Personality and Social Psychology Review, $21,361-388$.

Balliet, D., \& van Lange, P. A. M. (2013). Trust, conflict, and cooperation: A meta-analysis. Psychological Bulletin, 139, 1090-1112.

Barclay, P., \& Willer, R. (2007). Partner choice creates competitive altruism in humans. Proceedings of the Royal Society of London B: Biological Sciences, 274(1610), 749753.

Bates, D. M., Mächler, M., Bolker, B. M., \& Walker, S. C. (2014). Fitting linear mixedeffects models using lme4. Journal of Statistical Software, 67, 1-48.

Bendahan, S., Zehnder, C., Pralong, F. P., \& Antonakis, J. (2015). Leader corruption depends on power and testosterone. Leadership Quarterly, 26, 101-122.

Berry, J. W. (1967). Independence and conformity in subsistence-level societies. Journal of Personality and Social Psychology, 7, 415-418.

Berscheid, E., Snyder, M., \& Omoto, A. M. (1989). The relationship closeness inventory: Assessing the closeness of interpersonal relationships. Journal of Personality and Social Psychology, 57(5), 792-807.

Boehm, C. (2009). Hierarchy in the Forest: The Evolution of Egalitarian Behavior. Cambridge: Harvard University Press.

Bolger, N., \& Laurenceau, J.-P. (2013). Intensive longitudinal methods: An introduction to diary and experience sampling research. New York, NY: Guilford.

Brackett, M. A., Warner, R. M., \& Bosco, J. S. (2005). Emotional intelligence and relationship quality among couples. Personal Relationships, 12(2), 197-212.

Camerer, C. F. (2003). Behavioral Game Theory: Experiments in Strategic Interaction. Princeton: Princeton University Press. 
449

450

451

452

453

454

455

456

457

458

459

460

461

462

463

464

465

466

467

468

469

470

471

Castro-Schilo, L., \& Grimm, K. J. (2018). Using residualized change versus difference scores for longitudinal research. Journal of Social and Personal Relationships, 35(1), 32-58.

Chang, W. (2014). extrafont: Tools for using fonts. [Computer software]. Retrieved from https://CRAN.R-project.org/package=extrafont

Chen, S., Lee-Chai, A. Y., \& Bargh, J. A. (2001). Relationship orientation as a moderator of the effects of social power. Journal of Personality and Social Psychology, 80, 173-187.

Columbus, S., Molho, C., Righetti, F., \& Balliet, D. (in prep.). The interdependence in daily life study. Manuscript in preparation.

Columbus, S., Münich, J., \& Gerpott, F. H. (2020). Playing a different game: Situation perception mediates framing effects on cooperative behaviour. Journal of Experimental Social Psychology, 90, 1-14. doi:10.1016/j.jesp.2020.104006

Columbus, S., Norget, J., Balliet, D., \& Mayer, A. (in prep.). The nature and antecedents of situation characteristics. Manuscript in preparation.

Columbus, S., Thielmann, I., \& Balliet, D. (2019). Situational affordances for prosocial behaviour. On the interaction between Honesty-Humility and (perceived) interdependence. European Journal of Personality, 33(6), 655-673

Conner, T. S., \& Mehl, M. R. (2011). Handbook of Research Methods for Studying Daily Life. New York, NY: Guilford.

Coombs, C. H. (1973). A reparameterization of the prisoner's dilemma game. Behavioral Science, 18(6), 424-428.

Côté, S., Kraus, M. W., Cheng, B. H., Oveis, C., Van der Löwe, I., Lian, H., \& Keltner, D. (2011). Social power facilitates the effect of prosocial orientation on empathic accuracy. Journal of Personality and Social Psychology, 101(2), 217-232. 
472 Cranford, J. A., Shrout, P. E., Iida, M., Rafaeli, E., Yip, T., \& Bolger, N. (2006). A procedure for evaluating sensitivity to within-person change: Can mood measures in diary studies detect change reliably? Personality and Social Psychology Bulletin, 32(7), 917-929.

Crawford, S. E., \& Ostrom, E. (1995). A grammar of institutions. American Political Science Review, 89(3), 582-600.

Cronk, L., \& Leech, B. L. (2013). Meeting at Grand Central: Understanding the social and evolutionary roots of cooperation. Princeton, NJ: Princeton University Press.

Cross, E. J., Overall, N. C., Low, R. S., \& McNulty, J. K. (2019). An interdependence account of sexism and power: Men's hostile sexism, biased perceptions of low power, and relationship aggression. Journal of Personality and Social Psychology, 117(2), $338-363$.

Dawkins, M. S. (2010). Do asymmetries destabilize the Prisoner's Dilemma and make reciprocal altruism unlikely? Animal Behaviour, 80(2), 339-341.

de Cremer, D., \& van Dijk, E. (2005). When and why leaders put themselves first: Leader behaviour in resource allocations as a function of feeling entitled. European Journal of Social Psychology, 35, 553-563.

Decuyper, M., De Bolle, M., \& De Fruyt, F. (2012). Personality similarity, perceptual accuracy, and relationship satisfaction in dating and married couples. Personal Relationships, 19(1), 128-145.

Decuyper, M., Gistelinck, F., Vergauwe, J., Pancorbo, G., \& De Fruyt, F. (2018). Personality pathology and relationship satisfaction in dating and married couples. Personality Disorders: Theory, Research, and Treatment, 9(1), 81-92.

de Dreu, C. K. W. (2010). Social conflict: The emergence and consequences of struggle and negotiation. In S.T. Fiske, D. T. Gilbert, \& L. Gardner (Eds.), Handbook of Social Psychology (pp. 983-1023). New York: Wiley. 
de Dreu, C. K. W., \& Carnevale, P. J. (2003). Motivational Bases of Information Processing and Strategy in Conflict and Negotiation. In M. P. Zanna (Ed.), Advances in experimental social psychology (Vol. 35, pp. 235-291). Burlington, MA: Academic Press.

de Dreu, C. K. W., \& Weingart, L. R. (2003). Task versus relationship conflict, team performance, and team member satisfaction: a meta-analysis. Journal of Applied Psychology, 88(4), 741-749.

Delton, A. W., Krasnow, M. M., Cosmides, L., \& Tooby, J. (2011). Evolution of direct reciprocity under uncertainty can explain human generosity in one-shot encounters. Proceedings of the National Academy of Sciences, 108, 13335-13340.

Dowle, M., \& Srinivasan, A. (2019). data.table: Extension of 'data.frame`. [Computer software]. Retrieved from https://CRAN.R-project.org/package=data.table.

Durante, K. M., Eastwick, P. W., Finkel, E. J., Gangestad, S. W., \& Simpson, J. A. (2016). Pair-bonded relationships and romantic alternatives: Toward an integration of evolutionary and relationship science perspectives. In J. M. Olson \& M. P. Zanna (Eds.), Advances in Experimental Social Psychology (Vol. 53, pp. 1-74). Burlington, MA: Academic Press.

Edwards, L. J., Muller, K. E., Wolfinger, R. D., Qaqish, B. F., \& Schabenberger, O. (2008) An $\mathrm{R}^{2}$ statistic for fixed effects in the linear mixed model. Statistics in Medicine, 27, $6137-6157$.

Fast, N. J., \& Chen, S. (2009). When the boss feels inadequate: Power, incompetence, and aggression. Psychological Science, 20(11), 1406-1413.

Fehr, E., \& Gächter, S. (2002). Altruistic punishment in humans. Nature, 415(6868), 137140. 
521

522

523

524

525

526

527

528

529

530

531

532

533

534

535

536

537

538

539

540

541

542

543

544

545

Fiske, S. T. (2010). Interpersonal stratification: Status, power, and subordination. In S. T. Fiske, D. T. Gilbert, \& G. Lindzey (Eds.), Handbook of Social Psychology (pp. 941982). New York: Wiley.

Fletcher, G. J., \& Kerr, P. S. (2010). Through the eyes of love: reality and illusion in intimate relationships. Psychological Bulletin, 136(4), 627-658.

Foulk, T. A., Chighizola, N., \& Chen, G. (2020). Power corrupts (or does it?): An examination of the boundary conditions of the antisocial effects of experienced power. Social and Personality Psychology Compass, e12524.

Fox., J., \& Weisberg, S. (2019). A R Companion to Applied Regression ( $3^{\text {rd }}$ ed.). Thousand Oaks, CA: Sage.

Funder, D. C. (2016). Taking situations seriously: The situation construal model and the Riverside Situational Q-Sort. Current Directions in Psychological Science, 25(3), 203208.

Furr, R. M. (2008). A framework for profile similarity: Integrating similarity, normativeness, and distinctiveness. Journal of Personality, 76, 1267-1316.

Gächter, S., \& Schulz, J. F. (2016). Intrinsic honesty and the prevalence of rule violations across societies. Nature, 531(7595), 496-499.

Gaertner, L., \& Schopler, J. (1998). Perceived ingroup entitativity and intergroup bias: An interconnection of self and others. European Journal of Social Psychology, 28(6), 963980.

Galinsky, A. D., Rucker, D. D., \& Magee, J. C. (2015). Power: Past findings, present considerations, and future directions. In M. Mikulincer, P. R. Shaver, J. A. Simpson, \& J.F. Dovidio (Eds.), APA Handbook of Personality and Social Psychology, Volume 3: Interpersonal relations (pp. 421-460). Washington, DC: American Psychological Association. 
546 Gelfand, M. J., Raver, J. L., Nishii, L., Leslie, L. M., Lun, J., Lim, B. C., ... \& Aycan, Z. 547 (2011). Differences between tight and loose cultures: A 33-nation study. Science, 332(6033), 1100-1104.

549

550

551

552

553

554

555

556

557

558

559

560

561

562

563

564

565

566

567

568

569

Gerpott, F. H., Balliet, D., Columbus, S., Molho, C., \& de Vries, R. E. (2018). How do people think about interdependence? A multidimensional model of subjective outcome interdependence. Journal of Personality and Social Psychology, 115, 716-742.

Gonzaga, G. C., Campos, B., \& Bradbury, T. (2007). Similarity, convergence, and relationship satisfaction in dating and married couples. Journal of Personality and Social Psychology, 93(1), 34-48.

Gordon, A. M., \& Chen, S. (2013). Does power help or hurt? The moderating role of selfother focus on power and perspective-taking in romantic relationships. Personality and Social Psychology Bulletin, 39(8), 1097-1110.

Green, P., \& MacLeod, C. J. (2016). SIMR: An R package for power analysis of generalized linear mixed models by simulation. Methods in Ecology and Evolution, 7(4), 493-498.

Greer, L. L., van Bunderen, L., \& Yu, S. (2017). The dysfunctions of power in teams: A review and emergent conflict perspective. Research in Organizational Behavior, 37, $103-124$.

Halevy, N., Chou, E. Y., \& Galinsky, A. D. (2011). A functional model of hierarchy: Why, how, and when vertical differentiation enhances group performance. Organizational Psychology Review, 1(1), 32-52.

Halevy, N., Chou, E. Y., \& Murnighan, J. K. (2012). Mind games: the mental representation of conflict. Journal of Personality and Social Psychology, 102, 132-148.

Halevy, N., \& Phillips, L. T. (2015). Conflict templates in negotiations, disputes, joint decisions, and tournaments. Social Psychological and Personality Science, 6, 13-22. 
570 Handgraaf, M. J., van Dijk, E., Vermunt, R. C., Wilke, H. A., \& de Dreu, C. K. (2008). Less power or powerless? Egocentric empathy gaps and the irony of having little versus no power in social decision making. Journal of Personality and Social Psychology, 95, 1136-1149.

Hardin, G. (1968). The tragedy of the commons. Science, 162, 1243-1248.

Hauser, O. P., Hilbe, C., Chatterjee, K., \& Nowak, M. A. (2019). Social dilemmas among unequals. Nature, 572(7770), 524-527.

Henrich, J. (2014) Rice, psychology, and innovation. Science, 344, 593-594.

Henrich, J., Heine, S. J., \& Norenzayan, A. (2010). The weirdest people in the world? Behavioral and Brain Sciences, 33(2-3), 61-83.

Henry, L., \& Wickham, H. (2019). purrr: Functional Programming Tools. [Computer software]. Retrieved from https://CRAN.R-project.org/package=purrr

Hilbig, B. E., Kieslich, P. J., Henninger, F., Thielmann, I., \& Zettler, I. (2018). Lead us (not) into temptation: Testing the motivational mechanisms linking Honesty-Humility to cooperation. European Journal of Personality, 32(2), 116-127.

Hobbes, T. (2013). Leviathan: Or the Matter, Forme, and Power of a Common-Wealth Ecclesiasticall and Civill. Salt Lake City: Project Gutenberg. (Original work published $1651)$.

Holmes, J. G. (2002). Interpersonal expectations as the building blocks of social cognition: An interdependence theory perspective. Personal Relationships, 9(1), 1-26.

IBM Corp. (2017). IBM SPSS Statistics for Windows (Version 25.0). Armonk, NY: IBM Corp.

International Labour Organization (2016). International Standard Classification of Occupations. Retrieved from: https://www.ilo.org/public/english/bureau/stat/isco/intro.htm 
595

596

597

598

599

600

601

602

603

604

605

606

607

608

609

610

611

612

613

614

615

616

617

Janssen, O., van de Vliert, E., \& Veenstra, C. (1999). How task and person conflict shape the role of positive interdependence in management teams. Journal of Management, 25(2), 117-141.

Kelley, H. H., Holmes, J. G., Kerr, N. L., Reis, H. T., Rusbult, C. E., \& van Lange, P. A. M. (2003) An Atlas of Interpersonal Situations. Cambridge: Cambridge University Press.

Kelley, H. H., \& Thibaut, J. W. (1978). Interpersonal Relations: A theory of interdependence. New York, NY: John Wiley \& Sons.

Kenny, D. A., Kashy, D. A., \& Cook, W. L. (2006). Dyadic Data Analysis. New York, NY: Guilford.

Kim, J. J., Visserman, M. L., \& Impett, E. A. (2019). Power in close intimate relationships. In C. R. Agnew \& J. J. Harman (eds.), Power in Close Relationships (pp. 192-224). Cambridge, UK: Cambridge University Press.

Komorita, S. S., \& Parks, C. D. (1995). Interpersonal relations: Mixed-motive interaction. Annual Review of Psychology, 46(1), 183-207.

Kopelman, S. (2009). The effect of culture and power on cooperation in commons dilemmas: Implications for global resource management. Organizational Behavior and Human Decision Processes, 108, 153-163.

Kraus, M. W., \& Keltner, D. (2009). Signs of socioeconomic status: A thin-slicing approach. Psychological Science, 20(1), 99-106.

Kuznetsova, A., Brockhoff, P. B., \& Christensen, R. H. B. (2017). lmerTest package: Tests in linear mixed effects models. Journal of Statistical Software, 82, 1-26.

Le, B., \& Agnew, C. R. (2003). Commitment and its theorized determinants: A meta-analysis of the Investment Model. Personal Relationships, 10, 37-57. 
Le, B., Dove, N. L., Agnew, C. R., Korn, M. S., \& Mutso, A. A. (2010). Predicting nonmarital romantic relationship dissolution: A meta-analytic synthesis. Personal Relationships, 17, 377-390.

Lee, K., \& Ashton, M. C. (2017). Acquaintanceship and self/observer agreement in personality judgment. Journal of Research in Personality, 70, 1-5.

Lennon, C. A., Stewart, A. L., \& Ledermann, T. (2013). The role of power in intimate relationships. Journal of Social and Personal Relationships, 30, 95-114.

Lenth, R. V. (2016). Least-Squares Means: The R Package lsmeans. Journal of Statistical Software, 69(1), 1-33.

Long, J. A. (2019) interactions: Comprehensive, User-Friendly Toolkit for Probing Interactions. [Computer software]. Retrieved from https://CRAN.Rproject.org/package=interactions

Lüdecke, D. (2019). sjstats: Statistical Functions for Regression Models. [Computer software]. Retrieved from https://CRAN.R-project.org/package=sjstats

Makowski, D., Ben-Shachar, M. S., Patil, I., \& Lüdecke, D. (2020). correlation: Methods for Correlation Analysis. [Computer software]. Retrieved from https://github.com/easystats/correlation.

Molho, C., Balliet, D., \& Wu, J. (2019). Hierarchy, Power, and Strategies to Promote Cooperation in Social Dilemmas. Games, 10(1), 12.

Murray, H. A. (1938). Explorations in Personality. New York, NY: Oxford University Press.

Murray, S. L., \& Holmes, J. G. (2009). The architecture of interdependent minds: A motivation-management theory of mutual responsiveness. Psychological Review, 116(4), 908-928. 
641

642

643

644

645

646

647

648

649

650

651

652

653

654

655

656

657

658

659

660

661

662

663

664

665

Murray, S. L., Holmes, J. G., \& Pinkus, R. T. (2010). A smart unconscious? Procedural origins of automatic partner attitudes in marriage. Journal of Experimental Social Psychology, 46, 650-656.

Muthén, L. K., \& Muthén, B. O. (2017). Mplus User's Guide ( $8^{\text {th }}$ ed.). Los Angeles, CA: Muthén \& Muthén.

Nash, J. C., \& Varadhan, R. (2011). Unifying optimization algorithms to aid software system users: optimx for R. Journal of Statistical Software, 43(9), 1-14.

Nieper, A. S., Balliet, D., Molho, C., \& van Kleef, G. A. (2019). Power and cooperation: A meta-analytic review of economic games and distributive negotiations. Unpublished manuscript.

Nisbett, R. E., \& Cohen, D. (1996) Culture of Honor: The Psychology of Violence in the South. Boulder, CO: Westview Press.

North, D. C. (1991). Institutions, institutional change and economic performance. Cambridge, UK: Cambridge University Press.

Overall, N. C., Hammond, M. D., McNulty, J. K., \& Finkel, E. J. (2016). When power shapes interpersonal behavior: Low relationship power predicts men's aggressive responses to low situational power. Journal of Personality and Social Psychology, 111(2), 195-217.

Parks, C. D., Joireman, J., \& van Lange, P. A. (2013). Cooperation, trust, and antagonism: How public goods are promoted. Psychological Science in the Public Interest, 14(3), 119-165.

Pearce, J. L., \& Gregersen, H. B. (1991). Task interdependence and extrarole behavior: A test of the mediating effects of felt responsibility. Journal of Applied Psychology, 76(6), 838-844.

Pervin, L. A. (1978). Definitions, measurements, and classifications of stimuli, situations, and environments. Human Ecology, 6(1), 71-105. 
Pierce, G. R., Sarason, I. G., Sarason, B. R., Solky-Butzel, J. A., \& Nagle, L. C. (1997). Assessing the quality of personal relationships. Journal of Social and Personal Relationships, 14(3), 339-356.

Piff, P. K., Kraus, M. W., Côté, S., Cheng, B. H., \& Keltner, D. (2010). Having less, giving more: the influence of social class on prosocial behavior. Journal of Personality and Social Psychology, 99(5), 771-784.

Pinheiro, J., Bates, D., DebRoy, S., \& Sarkar, D., \& R Core Team (2019). nlme: linear and nonlinear mixed effects models. [Computer software]. Retrieved from https://CRAN. Rproject. org/package $=$ nlme.

Pinker, S. (2011). The Better Angels of Our Nature: The Decline of Violence in History and Its Causes. New York: Viking.

Powers, S. T., van Schaik, C. P., \& Lehmann, L. (2016). How institutions shaped the last major evolutionary transition to large-scale human societies. Philosophical Transactions of the Royal Society B: Biological Sciences, 371(1687), 20150098.

Rapoport, A., \& Chammah, A. M. (1965). Prisoner's Dilemma: A study in conflict and cooperation. Ann Arbor, MI: University of Michigan Press

Rauthmann, J. F. (2012). You say the party is dull, I say it is lively: A componential approach to how situations are perceived to disentangle perceiver, situation, and perceiverx situation variance. Social Psychological and Personality Science, 3(5), 519-528.

Rauthmann, J. F., \& Sherman, R. A. (2019). Toward a Research Agenda for the Study of Situation Perceptions: A Variance Componential Framework. Personality and Social Psychology Review, 23(3), 238-266.

Rauthmann, J. F., Sherman, R. A., \& Funder, D. C. (2015). Principles of situation research: Towards a better understanding of psychological situations. European Journal of Personality, 29, 363-381. 
691

692

693

694

695

696

697

698

699

700

701

702

703

704

705

706

707

708

709

710

711

712

713

Rauthmann, J. F., Sherman, R. A., Nave, C. S., \& Funder, D. C. (2015). Personality-driven situation experience, contact, and construal: How people's personality traits predict characteristics of their situations in daily life. Journal of Research in Personality, 55, 98-111.

R Core Team (2017). R 3.4.1. Vienna, Austria: R Foundation for Statistical Computing.

Reis, H. T. (2008). Reinvigorating the concept of situation in social psychology. Personality and Social Psychology Review, 12, 311-329.

Righetti, F., Gere, J., Hofmann, W., Visserman, M. L., \& van Lange, P. A. M. (2016). The burden of empathy: partners' responses to divergence of interests in daily life. Emotion, $16,684-690$.

Righetti, F., \& Impett, E. (2017). Sacrifice in close relationships: Motives, emotions, and relationship outcomes. Social and Personality Psychology Compass, 11, e12342.

Righetti, F., Luchies, L. B., van Gils, S., Slotter, E. B., Witcher, B., \& Kumashiro, M. (2015). The prosocial versus proself power holder: How power influences sacrifice in romantic relationships. Personality and Social Psychology Bulletin, 41, 779-790.

Roberts, G. (2005). Cooperation through interdependence. Animal Behaviour, 70, 901-908.

Ronay, R., Greenaway, K., Anicich, E. M., \& Galinsky, A. D. (2012). The path to glory is paved with hierarchy: When hierarchical differentiation increases group effectiveness. Psychological Science, 23, 669-677.

Roos, P., Gelfand, M., Nau, D., \& Lun, J. (2015). Societal threat and cultural variation in the strength of social norms: An evolutionary basis. Organizational Behavior and Human Decision Processes, 129, 14-23.

Rousseau, J.-J. (2004). A Discourse upon the Origin and the Foundation of Inequality Among Mankind. Salt Lake City: Project Gutenberg. (Original work published 1754). 
Rozin, P. (2001). Social psychology and science: Some lessons from Solomon Asch. Personality and Social Psychology Review, 5(1), 2-14.

Rozin, P. (2006). Domain denigration and process preference in academic psychology. Perspectives on Psychological Science, 1(4), 365-376.

Rusbult, C. E., Martz, J. M., \& Agnew, C. R. (1998). The investment model scale: Measuring commitment level, satisfaction level, quality of alternatives, and investment size. Personal Relationships, 5(4), 357-387.

Rusbult, C. E., \& van Lange, P. A. M. (2003). Interdependence, interaction, and relationships. Annual Review of Psychology, 54, 351-375.

Saffrey, C., Bartholomew, K., Scharfe, E., Henderson, A. J., \& Koopman, R. (2003). Self-and partner-perceptions of interpersonal problems and relationship functioning. Journal of Social and Personal Relationships, 20(1), 117-139.

Sherman, R. A., Nave, C. S., \& Funder, D. C. (2010). Situational similarity and personality predict behavioral consistency. Journal of Personality and Social Psychology, 99(2), $330-343$.

Sherman, R. A., \& Serfass, D. G. (2015) The comprehensive approach to analyzing multivariate constructs. Journal for Research in Personality, 54, 40-50.

Simpson, J. A. (2007). Psychological foundations of trust. Current Directions in Psychological Science, 16(5), 264-268.

Simpson, J. A., Farrell, A. K., Oriña, M. M., \& Rothman, A. J. (2015). Power and social influence in relationships. In M. Mikulincer \& P. R. Shaver (Eds.), APA handbook of personality and social psychology, Volume 3: Interpersonal relations. (pp. 393-420). Washington, D.C.: American Psychological Association.

Simpson, J. A., Rholes, W. S., \& Phillips, D. (1996). Conflict in close relationships: An attachment perspective. Journal of Personality and Social Psychology, 71, 899-914. 
Sivanathan, N., Pillutla, M. M., \& Murnighan, J. K. (2008). Power gained, power lost. Organizational Behavior and Human Decision Processes, 105(2), 135-146.

Skyrms, B. (2004). The Stag Hunt and the Evolution of Social Structure. Cambridge, UK: Cambridge University Press.

Smith, P. K., \& Hofmann, W. (2016). Power in everyday life. Proceedings of the National Academy of Sciences, 113, 10043-10048.

Snidal, D. (1985). Coordination versus prisoners' dilemma: Implications for international cooperation and regimes. American Political Science Review, 79, 923-942.

Spadaro, G., Tiddi, I., Columbus, S., ten Teije, A., van Harmelen, F., \& Balliet, D. (2020). The Cooperation Databank. Raw Data, VU Amsterdam.

Statistics Netherlands (2016). Annual Report on Integration 2016. Summary. The Hague, The Netherlands: Statistics Netherlands. Retrieved from https://cbs.nl//media/_pdf/2016/47/ji2016s_web.pdf

Steegen, S., Tuerlinckx, F., Gelman, A., \& Vanpaemel, W. (2016). Increasing transparency through a multiverse analysis. Perspectives on Psychological Science, 11(5), 702-712.

Talhelm, T., Zhang, X., Oishi, S., Shimin, C., Duan, D., Lan, X., \& Kitayama, S. (2014). Large-scale psychological differences within China explained by rice versus wheat agriculture. Science, 344(6184), 603-608.

Thielmann, I., Spadaro, G., \& Balliet, D. (2020). Personality and prosocial behavior: A theoretical framework and meta-analysis. Psychological Bulletin, 146(1), 30-90.

Thomas, K. A., DeScioli, P., Haque, O. S., \& Pinker, S. (2014). The psychology of coordination and common knowledge. Journal of Personality and Social Psychology, $107,657-676$.

Thompson, L., \& Hastie, R. (1990). Social perception in negotiation. Organizational Behavior and Human Decision Processes, 47, 98-123. 
Tingley, D., Yamamoto, T., Hirose, K., Keele, L., \& Imai, K. (2014) mediation: R package for causal mediation analysis. Journal of Statistical Software, 59, 1-38.

Tomasello, M., Melis, A. P., Tennie, C., Wyman, E., \& Herrmann, E. (2012). Two key steps in the evolution of human cooperation: The interdependence hypothesis. Current Anthropology, 53, 673-692.

van Kleef, G. A., de Dreu, C. K., \& Manstead, A. S. (2010). An interpersonal approach to emotion in social decision making: The emotions as social information model. In M. Zanna, Advances in Experimental Social Psychology (Vol. 42, pp. 45-96). Cambridge, MA: Academic Press.

van Lange, P. A. M., Balliet, D., Parks, C. D., \& van Vugt, M. (2014). Social dilemmas: Understanding human cooperation. Oxford, UK: Oxford University Press.

van Lange, P. A. M., Klapwijk, A., \& van Munster, L. M. (2011). How the shadow of the future might promote cooperation. Group Processes \& Intergroup Relations, 14, 857870.

van Lange, P. A. M., Rusbult, C. E., Drigotas, S. M., Arriaga, X. B., Witcher, B. S., \& Cox, C. L. (1997). Willingness to sacrifice in close relationships. Journal of Personality and Social Psychology, 72, 1373-1395.

Visserman, M. L., Righetti, F., Muise, A., Impett, E. A., Joel, S., \& van Lange, P. A. M. (2020). Taking Stock of Reality: Biased Perceptions of the Costs of Romantic Partners' Sacrifices. Social Psychological and Personality Science, 1948550619896671.

West, T. V., \& Kenny, D. A. (2011). The truth and bias model of judgment. Psychological Review, 118(2), 357-378.

Wickham, H. (2007). Reshaping Data with the reshape Package. Journal of Statistical Software, 21(12), 1-20. 
790

791

792

793

794

795

796

797

798

799

800

801

802

803

804

805

806

807

Wickham, H. (2011). The Split-Apply-Combine Strategy for Data Analysis. Journal of Statistical Software, 40(1), 1-29.

Wickham, H. (2016). ggplot2: Elegant Graphics for Data Analysis. New York: Springer.

Wickham, H. (2018). scales: Scale Functions for Visualization. [Computer software]. Retrieved from https://CRAN.R-project.org/package=scales

Wickham, H., François, R., Henry, L., \& Müller, K. (2019). dplyr: A Grammar of Data Manipulation. [Computer software]. Retrieved from https://CRAN.Rproject.org/package $=$ dplyr

Wickham, H., \& Henry, L. (2019). tidyr: Easily Tidy Data with 'spread()' and 'gather()' Functions. [Computer software]. Retrieved from https://CRAN.Rproject.org/package=tidyr

Wieselquist, J., Rusbult, C. E., Foster, C. A., \& Agnew, C. R. (1999). Commitment, prorelationship behavior, and trust in close relationships. Journal of Personality and Social Psychology, 77(5), 942-966.

Yamagishi, T. (2011). Trust: The evolutionary game of mind and society. Tokyo, Japan: Springer.

Yamagishi, T., Jin, N., \& Kiyonari, T. (1999). Bounded generalized reciprocity: Ingroup boasting and ingroup favoritism. Advances in Group Processes, 16, 161-197. 


\section{Footnotes}

${ }^{1}$ Here, we use the labels mutual dependence, conflict of interests, relative power, and coordination to represent dimensions of subjective interdependence which respectively

811 correspond to the constructs of interdependence, covariation of interests, asymmetric

812 dependence, and the basis of interdependence, as described in Interdependence Theory

813 (Kelley et al., 2003).

$814 \quad{ }^{2}$ The vast majority of theory on cooperation in conflict-of-interests situations has

815 attended to interactions involving equal power (Dawkins, 2010; Hauser, Hilbe, Chatterjee, \&

816 Nowak, 2019). Empirical research has largely followed theory: Out of 2,649 studies on

817 cooperation using social dilemmas conducted between 1958 and 2017, 90.50\% examined

818 situations involving equal power (Spadaro et al., 2020).

$819{ }^{3}$ Importantly, these results are robust for a large number of statistical controls, which

820 we report in the SI. In particular, although there were some demographic differences in what

821 kinds of situations people experience, the basic associations of mutual dependence, conflict

822 of interests, and relative power with cooperation are robust across genders, age, country of origin, and socio-economic status. 